Portland State University

PDXScholar

7-2-1997

\title{
The Role of the Hepatic Vagus in the Pathogenesis of Fever
}

Christopher Todd Simons

Portland State University

Follow this and additional works at: https://pdxscholar.library.pdx.edu/open_access_etds

Part of the Biology Commons

Let us know how access to this document benefits you.

\section{Recommended Citation}

Simons, Christopher Todd, "The Role of the Hepatic Vagus in the Pathogenesis of Fever" (1997). Dissertations and Theses. Paper 5697.

https://doi.org/10.15760/etd.7559

This Thesis is brought to you for free and open access. It has been accepted for inclusion in Dissertations and Theses by an authorized administrator of PDXScholar. Please contact us if we can make this document more accessible: pdxscholar@pdx.edu. 


\section{THESIS APPROVAL}

The abstract and thesis of Christopher Todd Simons for the Master of Science in Biology were presented July 2, 1997, and accepted by the thesis committee and the department.

COMMITTEE APPROVALS:

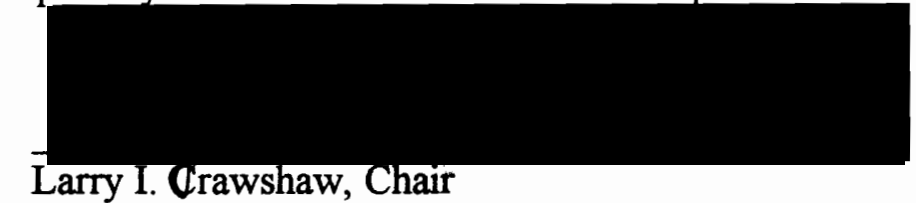

Larry 1. Crawshaw, Chair

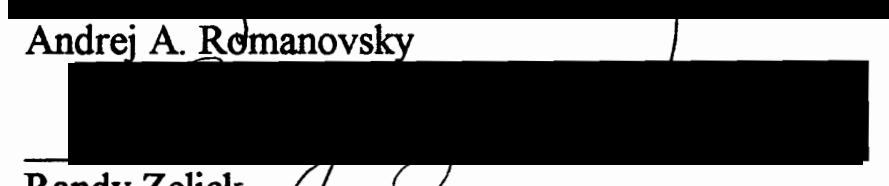

Randy Zelick O
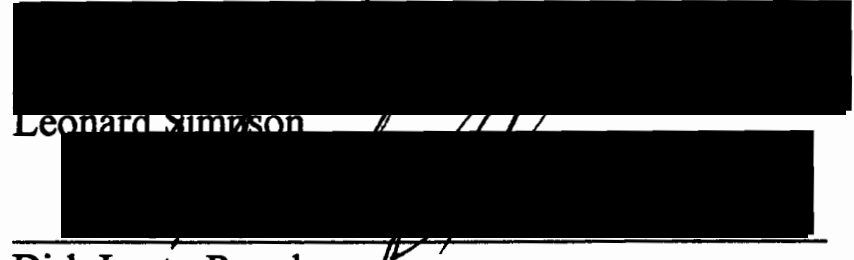

Dirk Iwata-Rueyl

Representative of the Office of Graduate Studies

DEPARTMENT APPROVAL:

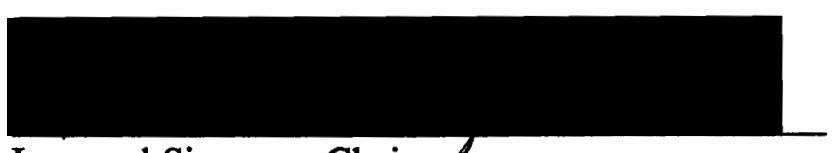

Leonard Simpson, Chair

Department of Biology

\section{ACCEPTED FOR PORTLAND STATE UNIVERSITY BY THE LIBRARY} on

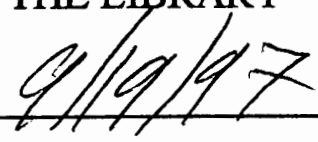




\section{ABSTRACT}

An abstract of the thesis of Christopher Todd Simons for the Master of Science in Biology presented July 2, 1997.

Title: The Role of the Hepatic Vagus in the Pathogenesis of Fever.

Recent evidence has suggested a role of vagal afferents in the pathogenesis of fever. Although bilateral truncal subdiaphragmatic vagotomy has been shown to attenuate the febrile response to lipopolysaccharide (LPS) and interleukin-1, no study has yet been able to verify which of the five subdiaphragmatic vagal branches (viz., the anterior and posterior celiac branches, the anterior and posterior gastric branches, and the hepatic branch) is responsible for communicating this signal. The present study tested the hypothesis that the hepatic vagal branch mediates pyrogenic signals from the periphery to the brain. Male Wistar rats underwent one of four selective vagotomiesceliac branch vagotomy (CBV), gastric branch vagotomy (GBV), hepatic branch vagotomy (HBV), or sham vagotomy (SV). On day 26-29 postvagotomy, a catheter was implanted into the right jugular vein. On day 29-32, the thermal responsiveness of each rat to LPS ( 0 or $1 \mu \mathrm{g} / \mathrm{kg}$; iv) was tested at $30^{\circ} \mathrm{C}$. Colonic temperatures $\left(\mathrm{T}_{\mathrm{c}}\right)$ were measured in lightly restrained animals using thermocouples. Three days later, the animals were subjected to a $24 \mathrm{~h}$ food and water deprivation, and the effectiveness of 
$\mathrm{CBV}, \mathrm{GBV}, \mathrm{HBV}$, and SV to increase gastric mass, induce pancreatic hypertrophy, and to block the porto-renal osmotic reflex was assessed by weighing the stomach and pancreas and measuring the specific gravity of bladder urine, respectively. Stomach mass, pancreatic hypertrophy and urine specific gravity separated the four treatment groups into four different clusters $(P=0.020)$, thus confirming that each type of vagotomy had its own effect on these parameters. The responses of the SV, CBV, and GBV rats to LPS were different from that of the HBV group $(P=0.022)$. After a latency of ca. $40 \mathrm{~min}, \Delta \mathrm{T}_{\mathrm{c}}$ rose, reaching a peak of $0.7 \pm 0.1^{\circ} \mathrm{C}, 0.6 \pm 0.1^{\circ} \mathrm{C}$, and $0.9 \pm$ $0.2^{\circ} \mathrm{C}$, in the $\mathrm{SV}, \mathrm{CBV}$, and $\mathrm{GBV}$ groups, respectively. $\mathrm{HBV}$ rats, however, responded with an attenuated fever that reached a peak of $0.1 \pm 0.2^{\circ} \mathrm{C}$. Similarly, the fever index of the HBV group was smaller than that of the other groups $(P=0.022)$. These findings suggest the hepatic vagal branch mediates peripheral pyrogenic signals to the brain. 


\section{CHRISTOPHER TODD SIMONS}

\section{A thesis submitted in partial fulfillment of the} requirements for the degree of

\section{MASTER OF SCIENCE \\ in BIOLOGY}

Portland State University

1997 
To Dawn

Where do I begin... 


\section{ACKNOWLEDGMENTS}

I would like to thank Dr. V. A. Kulchitsky for his instruction on the vagotomy procedure and discussions leading to the development of this paper, Dr. N. Sugimoto for his assistance in the surgical preparation and instrumentation of the experimental animals, and Dr. M. Székely for his comments on the experimental protocol. I would also like to thank Legacy Health System for providing me with the monetary support to carry on these experiments. However, most of all I would like to thank Dr. A. A. Romanovsky for his training, patience, and support, and for providing me with the opportunity to develop my own scientific skills. 


\section{TABLE OF CONTENTS}

ACKNOWLEDGMENTS

LIST OF FIGURES

Chapter

1. INTRODUCTION . . . . . . . . . . . . . . . . . . . 1

Statement of the Problem . . . . . . . . . . . . . . 2

Importance of the Problem . . . . . . . . . . . . . . . . . . 2

Purpose of the Study . . . . . . . . . . . . . . . . . . . 3

Specific Aim of the Study . . . . . . . . . . . . . . . . . . 4

2. OVERVIEW . . . . . . . . . . . . . . . . 5

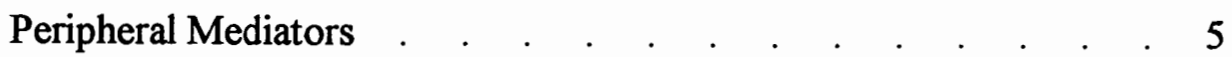

Current Concepts of Fever Pathogenesis . . . . . . . . . . 10

The Neural Pathway: An Emerging Concept . . . . . . . 12

3. METHODS . . . . . . . . . . . . . . . . 16

Animals . . . . . . . . . . . . . . . . . . . . 16

Surgical Preparation . . . . . . . . . . . . . . . . . 16

Perioperative Care . . . . . . . . . . . . . . . . . . 18

Experimental Protocol . . . . . . . . . . . . . . . . . . . 19

Effectiveness of Vagotomy. . . . . . . . . . . . . . . . . 20

Data Processing and Analysis . . . . . . . . . . . . . 20

4. RESULTS. . . . . . . . . . . . . . . . 22

Febrile Responsiveness . . . . . . . . . . . . . . . . . 22

Effectiveness of Vagotomy. . . . . . . . . . . . . . . $\quad$. 23 
5. DISCUSSION. . . . . . . . . . . . . . . . . . 36

The Effect of Vagotomy on Fever . . . . . . . . . . . . $\quad$. 36

The Hepatic Branch and Fever . . . . . . . . . . . . . 37

Febrile Mechanism . . . . . . . . . . . . . . . . 40

6. SUMMARY . . . . . . . . . . . . . . . . . 43

7. PERSPECTIVES . . . . . . . . . . . . . . . . 44

8. REFERENCES . . . . . . . . . . . . . . . . 46 


\section{LIST OF FIGURES}

Figure Legends . . . . . . . . . . . . . . . . . 26

Figure 1 . . . . . . . . . . . . . . . . . . . . . . . . . 28

Figure 2 .

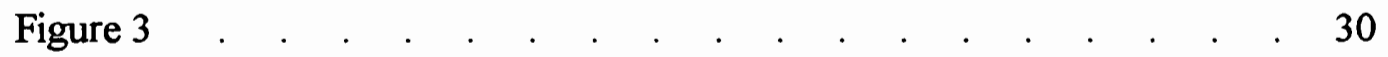

Figure 4 .

Figure 5 . . . . . . . . . . . . . . . . . . . . . 32

Figure 6 . . . . . . . . . . . . . . . . . . . . . 33

Figure 7 .

Figure 8 . 


\section{CHAPTER 1}

\section{INTRODUCTION}

Fever has long been regarded as a hallmark of disease. Indeed, the assessment of body temperature is still one of the cardinal indices used in medicine to determine disease severity. Over the last few decades, intensive fever research has uncovered a wealth of enlightening information. For instance, fever was redefined using the concept of setpoint to distinguish it from hyperthermia (Stitt 1979). Moreover, fever was shown to be adaptive; it decreases mortality (Kluger Ringler and Anver 1975) by enhancing many host defense responses.

Fever is thought to be initiated by exogenous pyrogens that gain access to the internal environment of the host. Upon their interaction with immune cells, these exogenous pyrogens cause the de novo synthesis and consequent release of the endogenous pyrogens (also known as pyrogenic cytokines). Once released, these endogenous mediators are thought to gain access to the brain and cause the release of the final febrile mediator-prostaglandin (PG) (presumably of the E series)-which acts by exciting the hypothalamic thermosensitive neurons in the hypothalamus (Bligh and Milton 1973, Crawshaw and Stitt 1975) that drive the heat loss and heat production effector mechanisms. It is not clear, however, how the pyrogenic cytokines gain access to the brain. Moreover, fever often begins before there is any increase in 
circulating levels of cytokines. Because of these inconsistencies, researchers have begun to look for alternative mechanisms.

Recently, a new model has been proposed that suggests peripheral neural afferentation may have a role in the genesis of a febrile response (Bluthé et al., 1994, Székely Balaskó and Romanovsky 1995, Watkins et al., 1995, Sehic and Blatteis 1996). Whether this mechanism functions in lieu of, or, in combination with the humoral model remains speculative; but it appears both mechanisms are capable of operating simultaneously (Romanovsky et al., The vagus nerve, in press).

\section{Statement of the Problem}

Emerging evidence suggests a role of the abdominal vagal afferents in transducing a peripheral pyrogenic signal to the brain (Watkins et al., 1995, Székely Balaskó and Romanovsky 1995). It has been shown that complete subdiaphragmatic truncal vagotomy attenuates the febrile response to a low dose of intravenous lipopolysaccharide (LPS) (Romanovsky et al., The vagus nerve, in press). It is unclear, however, which vagal branch is responsible for the signal transduction role of the abdominal vagus nerve.

\section{Importance of the Problem}

Identifying the specific branch responsible for mediating peripherally generated pyrogenic signals will provide a basis upon which the mechanism of febrile pathogenesis can be determined. 


\section{Purpose of the Study}

There are five major vagal branches: the anterior and posterior (accessory) celiac branches, the anterior and posterior gastric branches, and the hepatic branch. This study was undertaken in an effort to delineate which branch(es) is (are) important in transducing a pyrogenic signal from the periphery to the brain. A priori, there appears to be four possibilities. Individually, any one of the three branches may have the responsibility of mediating the afferent febrile signal. The intestinal tract is known to harbor many pathogenic bacteria, including Eschericia coli. Since this is a potentially rich source of pyrogenic stimuli, it is plausible that the celiac branch of the vagus mediates the pyrogenic signal. Moreover, the celiac branch has a very large receptor field that is capable of receiving stimuli from a wide area within the abdomen. The gastric branch also has a large receptor field and the gastric fundus was recently shown to secrete the pro-pyretic cytokine: interleukin (IL)-1 $\beta$ (Montuschi et al., 1996). Since vagus-associated paraganglia are known to have IL-1 receptors (Goehler et al., 1994), local concentrations of $\mathbb{L}-1 \beta$ produced by the gastric fundus may be high enough to trigger the neural febrile signal. The liver is intimately involved in acute phase responses (Trautwein Boker and Manns 1994) and the hepatic branch has been shown to mediate other sickness symptoms such as hyperalgesia (Watkins et al., Neurocircuitry, 1994). Hence, the hepatic vagal branch should also be considered. Alternatively, no single branch may be involved in the signal transduction. Instead, several, or all, of the branches may be needed to generate a signal strong enough to induce febrile pathogenesis.

Here, I hypothesize that it is the hepatic vagal branch that is responsible for conducting the pyrogenic signal from the periphery to the brain. Several lines of 
evidence support this hypothesis. First the liver is the principle organ responsible for neutralizing exogenous materials carried by the blood (Nakao et al., 1994, Mathison and Ulevitch 1979, Ogle et al., 1991); Kupffer cells, which phagocytize the exogenous pyrogens, are also capable of releasing various mediators that, in turn, could activate the hepatic vagal afferents (Nathan 1987, Decker 1990). Second, some sickness symptoms other than fever use the hepatic vagal branch as the avenue for signal transduction (Watkins et al., Neurocircuitry, 1994, Layé et al., 1995, Bluthè et al., 1996). Finally, it has recently been shown that animals with congested liver (as a result of chronic intraportal catheterization) respond to iv LPS with an attenuation of the first phase of biphasic fever (Székely et al. in press). When combined, these data lend support to the hypothesis that the hepatic vagal branch is responsible for conducting the peripheral pyrogenic signals to the brain.

\section{Specific Aim of the Study}

The specific aim of this study is to test the hypothesis that a pyrogenic signal reaches the brain through the hepatic vagal branch. 


\section{CHAPTER 2}

\section{OVERVIEW}

\section{Peripheral Mediators}

Currently, the prevailing theory of the pathogenesis of fever suggests that the febrile cascade is initiated by the appearance of exogenous pyrogens in the internal environment of the organism (Kluger 1991, Moltz 1993). There are two general types of the so-called exogenous pyrogens: Those that have their origin inside the body and those that originate outside the host. Examples of the former are bile acids and antibody-antigen complexes; while certainly capable of eliciting a febrile response, these pyrogens are fairly uncommon progenitors of fever (Dinarello and Wolff 1982, Murphy 1991, Nakamori et al. 1993). Examples of the latter include gram negative $[\operatorname{gr}(-)]$ and gram positive $[\mathrm{gr}(+)]$ bacteria, viruses, fungi, and various toxins and chemicals, among others (Dinarello and Wolff 1982, Kluger 1991). The vast majority of fevers result from substances that are foreign to the animal's internal environment.

With $\operatorname{gr}(-)$ bacteria, it is widely accepted that an outer cell wall component, LPS (endotoxin), is responsible for the pyrogenic nature of these cells. LPS, although species specific, has a few, important, common characteristics. All LPS molecules have an O-polysaccharide chain; this chain is highly variable but gives LPS its characteristic O-antigen immunological, but not pyrogenic, properties (Cooper 1987). All LPS molecules also have a core polysaccharide ( $R$-core) which is usually consistent within 
related bacterial strains. Mutant Salmonella strains that lack either the Opolysaccharide or the R-core are still pyrogenic (Dinarello and Wolff 1982). Finally, LPS has a lipid component, lipid-A, which is responsible for the pyrogenic action (Cooper 1987). It has been shown that when lipid-A is complexed to biologically inert carrier molecules (serum albumin) and injected into experimental animals, typical biphasic fever results (Reitschel et al., 1973).

Gram negative bacteria are also able to secrete pyrogenic exotoxins. However, the fever produced by this mechanism is generally masked by the overwhelming effects of LPS (Dinarello and Wolff 1982). Hence, fever in response to gr(-) infection is generally credited to the specific activity of LPS.

Like the $\operatorname{gr}(-)$ bacteria, the $\operatorname{gr}(+)$ bacteria can elicit a febrile response through cell wall components, specifically the muramyl peptides (Dinarello et al., 1978). They are also able to secrete powerful exotoxins. (Dinarello and Wolff 1982).

Because the exact mechanism by which viruses invoke fever is unknown, relatively few experimental models are available. This is despite the enormous prevalence of viral infections (Dinarello and Wolff 1982). Nevertheless, it has been demonstrated that hemeagglutinin (HA), the protein responsible for enabling the virus to enter susceptible cells, is important for pyrogenic activity. The specific HA locus responsible for febrigenesis, although undetermined, appears to be some lipidcarbohydrate moiety (Siegert and Braune 1964). Additionally, there has been some evidence suggesting that double-stranded RNA, produced during viral replication, may have pyrogenic effects (Krueger et al., 1988). Injection of the synthetic doublestranded RNA molecule, polyriboinosinic:polyribocytidylic acid, has also been shown to induce a typical febrile response (Krueger et al., 1988). 
It is generally understood that exogenous pyrogens, of themselves, are not directly responsible for the rise in body temperature during fever. Instead, they exert their action by inducing the de novo synthesis and release of endogenous pyrogens (pyrogenic cytokines) from activated monocytes and macrophages (Dinarello Cannon and Wolff 1988, Kluger 1991). How does this process occur? Circulating LPS is usually bound to a carrier, LPS-binding protein (LBP) (Kirkland 1993). In the presence of LBP, LPS binds to the cell surface protein CD14 (Gegner Ulevitch and Tobias 1995). Activation of the CD14 receptor triggers various cellular responses (Gegner Ulevitch and Tobias 1995). In particular, it may be responsible for the synthesis and release of the cytokines that further mediate the pyrogenic cascade (Wright et al., 1990).

Release of pyrogenic cytokines is accomplished by exocytosis, active transport, and cell death (Dinarello and Wolff 1993). Currently, it appears that there are four pyrogenic cytokines: $\mathbb{I L}-1$, tumor necrosis factor (TNF), interferon (INF), and IL-6. In vivo these cytokines act synergistically to initiate the febrile response (Moltz 1993). There are additional cytokines that also seem to be pyrogenic, including interleukin-2, interleukin-8, and macrophage inflammatory protein-1 (Kluger 1992). Further research needs to be done, however, to confirm their pyrogenicity and determine the mechanisms by which these cytokines work.

Interleukin-1. There are two forms of $\mathrm{L}-1: \alpha$ and $\beta$. Interestingly, despite only a twenty-six percent homology between the two forms, both $\alpha$ and $\beta$ seem to stimulate the same set of receptors (Kluger 1991, Moltz 1993). When injected intraperitoneally (ip), intravenously (iv), or intracerebroventricularly (icv), both $I L-1 \alpha$ and $\mathrm{IL}-1 \beta$ cause dose- dependent fevers (Dinarello Cannon and Wolff 1988, Kluger 
1991). However, $I L-1 \beta$ appears to have a higher level of specific activity compared to $\mathrm{IL}-1 \alpha$ (Dinarello Cannon and Wolff 1988), and antiserum to $\mathrm{IL}-1 \alpha$ does not attenuate LPS induced fever whereas anti-IL-1 $\beta$ antiserum does (Kluger 1991, Moltz 1993). Furthermore, it has been shown that $\mathbb{I L}-1 \alpha$ is produced at significantly lower levels than IL-1 $\beta$ (Dinarello Cannon and Wolff 1988, Moltz 1993). It is, therefore, believed that $\mathbb{L}-1 \beta$ and not $\mathbb{L}-1 \alpha$ is involved in the fever pathway (Kluger 1992). It should not be forgotten that $I L-1$ stimulates its own synthesis as well as that of other pyrogenic cytokines such as IFN- $\beta$, TNF- $\alpha$, and IL-6 (Lemay et al., In vivo evidence, 1990, Moltz 1993).

Tumor Necrosis Factor. TNF is the first cytokine released in response to infection (Zuckerman Shellhaas and Butler 1989) and like IL-1, it will induce fever when administered icv, iv or subcutaneously (Dinarello Cannon and Wolff 1988, Kluger 1991, Moltz 1993). The fevers are nearly identical to those induced by $\mathbb{I L}-1$; they are characterized by a relatively early onset and short duration. TNF has also been shown to induce the synthesis of $\mathbb{L}-1$ and $\mathbb{I L}-6$ (Dinarello et al., 1986, Shalaby et al., 1989). Several investigators have shown that attenuation of TNF levels with anti-TNF immunoglobulins results in decreased magnitudes of LPS fever (Nagai et al., 1988, Kawasaki et al., 1989, Shimozato Iwata and Tamura 1990).

Interferons. The three interferons $(\alpha, \beta$, and $\gamma)$ posses potent antiviral properties and are thought to be released, most readily, in response to viral challenges. IFN $\alpha$ and $\beta$ show significant amino acid homology while IFN $\gamma$ is distinct, sharing only seventeen percent amino acid similarity (Dinarello Cannon and Wolff 1988). When injected icv or iv, all IFNs produce dose dependent fevers (Dinarello Cannon and Wolff 1988, Moltz 1993). IFN $\alpha$, however, seems to have the highest activity followed by 
that IFN $\beta$ and $\gamma$, respectively. These fevers were quite different from those induced by IL-1 or TNF. First, it takes significantly higher IFN doses to induce the same magnitude of fever. It has been demonstrated that a $1{ }^{\circ} \mathrm{C}$ rise in the body temperature of rabbits following the iv injection of IFN $\alpha$ takes approximately $50 \mu \mathrm{g} / \mathrm{kg}$, whereas the same rise induced by $I L-1 \beta$ or TNF $\alpha$ require only $0.2 \mu \mathrm{g} / \mathrm{kg}$ and $0.5 \mu \mathrm{g} / \mathrm{kg}$, respectively (Dinarello et al., 1984). Second, the dynamics of IFN fever is different from that of fevers induced by IL-1 and TNF; IFN fevers are characterized by a delayed onset and a lower magnitude of body temperature rise (Dinarello et al., 1984). IFN does stimulate the production of IL-1 (Miossec and Ziff 1986, Trautwein Boker and Manns 1994).

Interleukin-6. When IL-6 is injected icv into rabbits, typical febrile responses occur. However, the concentrations of $I \mathrm{~L}-6(500 \mathrm{ng} / \mathrm{kg}-10 \mu \mathrm{g} / \mathrm{kg})$ needed to induce this rise in body temperature are significantly higher than those needed to induce fever as a result of $\mathbb{I L}-1$ or TNF injections (Kluger 1991). Pretreatment of rats with anti-IL6 antibody greatly attenuates the LPS fever (LeMay Vander and Kluger 1990). Furthermore, plasma $\mathbb{L}-6$ activity increases following pyrogenic doses of LPS: during the rise and plateau of the febrile response, a strong positive correlation was found between fever and plasma IL-6 concentrations (LeMay Vander and Kluger 1990). Circulating IL-6 seems to get protection from protease activity by binding to its carrier molecule, $\alpha-2$ macroglobulin; this binding does not affect the biologic activity of the IL-6 (Le and Vilcek 1989). 


\section{Current Concepts of Fever Pathogenesis}

Currently, febrile pathogenesis is thought to occur via a humoral pathway whereby the endogenous pyrogens travel to the brain via the blood. It is unclear, however, how these cytokines gain access to the central nervous system and elicit the release of PGE [it should, however, be mentioned that the cytokine-PGE line is not the only humoral propyretic pathway. Cholecystokinin octapeptide (Kandamy and Williams 1983), macrophage inflammatory protein-1 (Davatelis et al., 1989) and IL-8 (Rothwell Hardwick and Lindley 1990) are all thought to have central actions that are independent of PGE.]. Proinflammatory cytokines are relatively large (c.a. 17,000 KD) and highly lipophobic (Dinarello 1990). They are, therefore, unlikely to passively diffuse across the blood-brain barrier. Indeed, fluoresciene and radiolabeled cytokines have failed to show up within the anterior hypothalamus following systemic injection even though fever developed within twenty minutes (Blatteis 1992, Dinarello Weiner and Wolff 1978). How do the circulating pyrogenic cytokines send the propyretic signal to the brain? There are several hypotheses to explain this cytokine-to-brain communication.

The organum vasculosum laminae terminalis (OVLT) hypothesis. The importance of the OVLT for fever genesis has been shown in experiments with electrolytic lesions to this organ; such lesions have been shown to block the febrile response to systemic injections of LPS (Blatteis et al., 1983). The OVLT is a circumventricular organ that is located just rostral to the hypothalamic thermoregulatory center (the preoptic anterior hypothalamus; POA), in the anteroventral wall of the third ventricle. Like all circumventricular organs, the OVLT is devoid of the blood-brain barrier: it has particularly fenestrated capillaries that allow 
plasma ultrafiltration (Davson et al., 1993). Hence, pyrogenic cytokines could passively diffuse into the perivascular clefts of the this organ. It is unlikely however, that cytokines could travel to other brain regions because of the tight junctions between the ependymal cells that seal off the circumventricular organs from the rest of the brain (Krisch Leonhardt and Buchheim 1978, Watkins Maier and Goehler 1995). It is postulated that the pyrogenic cytokines have their effect by promoting cyclooxygenation and the subsequent release of $\mathrm{PGE}_{2}$ from the astrocytes surrounding the vascular network (Dascombe and Milton 1979). Being small and lipophillic, $\mathrm{PGE}_{2}$ could penetrate the tight junctions separating the OVLT from the rest of the brain (Blatteis 1992), bind to EP1-receptors on thermosensitive neurons (Oka and Hori 1994), and drive febrigenesis. Alternatively, cytokines (entering the OVLT) or $\mathrm{PGE}_{2}$ (formed within the OVLT) may excite neurons that project from the OVLT to the POA (Shibata and Blatteis 1991).

The Mediated Transport Hypothesis. The second proposed mechanism by which cytokines communicate the pro-inflammatory signal to the brain is by carriermediated transport across the blood-brain barrier. This same mechanism is seen in the transport of other substances into the brain, including amino acids, fatty acids, and transferrin (Watkins Maier and Goehler 1995). Indeed, separate, saturable transport mechanisms for $\mathbb{I L}-1, \mathbb{I L}-6$, and TNF have been found in rats and mice (Banks Plotkin and Kastin 1995). The amounts of cytokines entering the brain via this mechanism is, however, extremely small. It has been calculated that approximately $0.05 \%$ of the amount of iv injected TNF, $0.2 \%$ of the amount of iv injected IL- 6 , and $0.07 \%$ of the amount of iv injected IL-1 enters the brain (Watkins Maier and Goehler 1995). Thus, the physiological significance of this mechanism is in question. Therefore, even though 
some data support the mediated-transport hypothesis, there is still great uncertainty whether the amounts of cytokines entering the brain from the blood are sufficient to stimulate a febrile response (Blatteis and Sehic 1997).

\section{The Neural Pathway: An Emerging Concept}

The Vagus Nerve Hypothesis. The two mechanisms mentioned above require that some pyrogenic substances reach the brain through the blood. However, sickness symptoms (including fever) can occur in the absence of detectable blood levels of both LPS and proinflammatory cytokines (Kluger 1991). Moreover, following a peripheral injection of LPS, the febrile response often begins within 7-9 minutes (Kluger 1991). This short latency, however, is not consistent with the slow appearance of the humoral mediatory products. Indeed, the process of de novo synthesizing, releasing, and transporting cytokines is inherently time consuming and cannot be completed within this short time frame. By utilizing only "traditional" humoral mechanisms, there is no way to bypass this time consuming stage because exogenous pyrogens such as LPS are also unable to cross the blood-brain barrier in appreciable amounts (Cooper and Cranston 1963). Therefore, a faster, alternative mechanism has recently been proposed (Bluthé et al., 1994, Székely Balaskó and Romanovsky 1995, Watkins et al., 1995, Sehic and Blatteis 1996). This mechanism involves chemosensitive afferent fibers of the abdominal vagus.

It has recently been shown that afferent vagal activity is increased following the hepato-portal infusion of $\mathbb{I L}-1 \beta$ (Niijima 1992). Moreover, the vagus nerve has been implicated in mediating several symptoms of the pyrogen induced "sickness syndrome" (Romanovsky et al., 1996) including hyperalgesia (Watkins et al., Neurocircuitry, 
1994), anorexia (Eberle-Wang Levitt and Simansky 1993), and suppressed social behavior (Bluthé et al., 1994). More importantly, capsaicin desensitization of the intraabdominal nerve endings (Székely and Romanovsky 1997) as well as subdiaphragmatic vagotomy (Watkins et al., 1995, Sehic and Blatteis 1996, Romanovsky et al., Febrile responsiveness, in press) has been shown to result in the attenuation (or complete blockage) of the febrile response to a peripherally administered pyrogen. In addition, the LPS-induced expression of IL-1 $\beta$ mRNA in the brain of mice (Layé et al., 1995) and the intra-brain rise of $\mathrm{PGE}_{2}$ concentrations in the guinea pig (Sehic and Blatteis 1996) were also attenuated in vagotomized animals.

Although the data suggest a role for the vagus nerve in relaying peripheral pyrogenic signals to the brain, other interpretations are possible. Indeed, one potential mechanism by which vagotomy or capsaicin treatment could result in attenuated thermal responses is by the disruption of normal thermoeffector proficiency. These treatments may, of themselves, induce a thermoeffector deficiency occurring either secondarily to malnutrition (a common side effect of vagotomy) or in a malnutritionindependent way. If such a deficiency were to occur, the animals would be unable to respond with an adequate body temperature rise to a pyrogenic stimulus; they also would be unable to adequately respond to thermal stimulation (e.g.. cold exposure) or to nonthermal chemical stimulants (e.g., adrenergic agonists that directly activate several thermoeffector mechanisms including brown adipose tissue thermogenesis and skin vasoconstriction). However, it has been shown that healthy (non-malnourished) vagotomized or capsaicin desensitized rats are capable of responding to cold exposure and adrenomimetics normally (Székely and Romanovsky 1997, Romanovsky et al., 
Cold defense, in press). This suggests that vagotomy-induced thermoeffector insufficiency is not the cause of the febrile irresponsiveness to a pyrogenic signal.

Another possibility is that vagotomy per se may activate the endogenous antipyretic system. If this were the case, vagotomized animals would respond normally to thermal stimuli, but would not respond to a pyrogenic stimulus even if the stimulus is applied directly to the brain. Recently, this hypothesis has been rejected (Sugimoto et al., 1997). When either a low or a high dose of $\mathrm{PGE}_{2}$ was delivered icv, the vagotomized rats responded with the same degree of hyperthermia as their sham operated counterparts. Therefore, it appears that vagotomy-induced antipyresis cannot explain the attenuated fevers that result following subdiaphragmatic bilateral truncal vagotomy.

The role of the vagus nerve in transducing the pyrogenic signal from the periphery to the brain is dependent on the route of pyrogen administration (Goldbach Roth and Zeisberger 1997) as well as its concentration (Romanovsky et al., The vagus nerve, in press). The liver-originated, vagally carried signals may be important only when the pyrogen is initially concentrated in the hepato-portal region (or the peritoneal cavity in general) - whether exclusively [as following the ip administration (Goldbach Roth and Zeisberger 1997)] or predominantly [as following the iv administration in a low dose when the whole amount of injected pyrogen is successfully filtered from the blood by the liver (Mathison and Ulevitch 1979, Ogle et. al. 1991, Nakao et al., 1994)].

The hepato-portal region has been intimately associated with febrigenesis. IL-1 $\beta$ injections into the portal vein increase the afferent activity of the hepatic vagus (Niijima 1992). Moreover, when the liver Kupffer cells are inactivated by gadolinium chloride $\left(\mathrm{GdCl}_{3}\right)$ treatment, the fever resulting from iv LPS infusion is abolished 
$\left[\mathrm{GdCl}_{3}\right.$ is a selective inactivator of macrophages. Following its administration, Kupffer cell activity returns to normal at day 4 whereas all other macrophages resume normal activity at day 2 . Therefore, by administering LPS on day 3 , it is possible to study the selective effects of Kupffer cell inactivity (Sehic et al. 1996)]. It has also been demonstrated that the hepatic vagal branch is responsible for mediating the hyperalgesic effects of LPS (Watkins et. al., Neurocircuitry, 1994 Watkins et. al., Characterization of cytokine, 1994). Hyperalgesia, like fever, is a part of the sickness syndrome, a non-specific response to systemic inflammation. 
and then anesthetized with an ip injection of ketamine-xylazine-acepromazine (55.6, 5.5 , and $1.1 \mathrm{mg} / \mathrm{kg}$, respectively). Immediately thereafter, they were given a prophylactic injection of antibiotic (enrofloxacin $12 \mathrm{mg} / \mathrm{kg}, \mathrm{sc}$ ). The animal's head was placed into a stereotaxic device (Model 300, Kopf Instruments, Tujunga, CA) which was used to secure the position of the skull. A $1.5-\mathrm{cm}$-long incision was made over the saggital suture. The underlying connective tissue, portions of the temporalis muscle, and the periosteum were removed by scraping, thus exposing the underlying bone. The bone was cleansed with a $3 \%$ hydrogen peroxide solution and dried with $98 \%$ ethanol. Four small holes were drilled in the exposed bone and four miniature stainless steel screws were inserted into the holes. Dental acrylic was then poured over the four screws and exposed bone, allowed a few minutes to partly harden, and finally, shaped into a round, flat-surfaced platform.

The animals were randomly assigned to four equal-sized groups and underwent one of four selective vagotomies: celiac branch vagotomy (CBV), gastric branch vagotomy (GBV), hepatic branch vagotomy (HBV), or sham vagotomy (SV). In all cases, a midline laprotomy was made and the stomach and lower esophagus were retracted from the abdominal cavity and covered with sterile, saline-moistened gauze. For GBV, the anterior and posterior gastric branches were isolated and individually cut approximately $1 \mathrm{~cm}$ distal from their origin on their corresponding trunk (Fig. 1). Similarly, for $\mathrm{CBV}$, the posterior (accessory) celiac branch and the anterior celiac branch were individually cut approximately $5 \mathrm{~mm}$ distal to their origin with the corresponding vagal trunk (Fig. 1). For HBV, the liver was deflected to expose the hepatic vagal branch. The hepatic branch was then isolated and transected approximately $5 \mathrm{~mm}$ distal to its origin (Fig. 1). In SV, the vagal trunks were similarly 
exposed but not cut. At the end of the operation, another dose of enrofloxacin (12 $\mathrm{mg} / \mathrm{kg}$ ) was administered ip, and the laprotomy wound was sutured in two layers and cleansed with a $10 \%$ povidone-iodine solution. The rats were then allowed a $26-29 \mathrm{~d}$ recovery period.

Stage 2. Following the recovery period, the animals were again anesthetized (same as above) and given a prophylactic injection of antibiotic (enrofloxacin $24 \mathrm{mg} / \mathrm{kg}$, sc). A 1-cm-long incision was made on the ventral surface of the neck $1 \mathrm{~cm}$ to the right of the trachea. The muscles were retracted, and the right jugular vein was exposed, freed from its surrounding connective tissue, and ligated. A small silicone catheter $(0.5 \mathrm{~mm} \mathrm{ID}, 0.9 \mathrm{~mm} \mathrm{OD})$ filled with heparinzed $(100 \mathrm{U} / \mathrm{ml})$ pyrogen-free saline (PFS) was inserted into the superior vena cava through the jugular vein and secured with surgical thread. The free end of the catheter was tunneled under the skin and exteriorized at the base of the skull, at the edge of the acrylic platform. The catheter was then coiled and placed into a hollow pedestal which was affixed to the platform using dental acrylic and further protected with a screwed-on cap. The neck wound was sutured and cleansed with a $10 \%$ povidone-iodine solution. Following the

operation, the catheter was flushed with heparinized PFS every other day. The patency of the cannula was verified by the presence of blood in the catheter and low resistance to the PFS injection.

\section{Perioperative care}

During recovery from vagotomy, the animals were closely watched and fed highly palatable foods consisting of moistened chow and fruits. Their body weight was closely monitored. Rats that continued to lose body weight after $5 \mathrm{~d}$ postsurgery were 
not used in the experiments; for humane reasons, these rats were sacrificed with a lethal dose of pentobarbital.

\section{Experimental Protocol}

The febrile responsiveness to an iv injection of bacterial endotoxin (or time control) was tested 29-32 d following the selective vagotomy (or sham surgery). This time period allowed for adequate recovery from the surgical operations but was definitely too short for any physiologically meaningful regeneration of the vagus nerve (Powley et al., 1983).

On the day of the experiment, each animal was placed into its restrainer and instrumented with a colonic thermocouple (inserted to $9 \mathrm{~cm}$ beyond the anus). Thermocouples were connected to a data acquisitor (model TCA-A1-24, Dianachart; Rockaway, NJ) and thence to a computer. The rats were then placed into an environmental chamber (Forma Scientific; Marietta, $\mathrm{OH}$ ) set to an $\mathrm{T}_{\mathrm{a}}$ of $30^{\circ} \mathrm{C}$ (upper limit of thermoneutrality for rats) and a relative humidity of $50 \%$. The catheter was removed from the pedestal, uncoiled, and the free end of the catheter was pulled through a wall port and connected to a syringe. After a 1-h stabilization period, measurements were began and colonic temperature $\left(\mathrm{T}_{\mathrm{c}}\right)$ was recorded every two minutes for $5 \mathrm{~h}$, either with no injection (time control) or from $1 \mathrm{~h}$ before to $4 \mathrm{~h}$ after the iv injection of Eschericia coli 0111:B4 LPS (1 $\mu \mathrm{g} / \mathrm{kg}$; Sigma, St. Louis, MO) in PFS $(1 \mathrm{ml} / \mathrm{kg})$. Each rat was used in two experiments. One half of each group received LPS first; three days later they were used again in time control studies. The other half of each group received LPS in a counterbalanced order, i.e., time control followed by LPS. 


\section{Effectiveness of Vagotomy}

Effectiveness of vagotomy was verified using the following criteria. An increase in stomach weight was used to assess GBV (gastric vagotomy is known to cause smooth muscle paralysis which results in the inhibition of the evacuatory function of the stomach; see Ellis and Pryse-Davies 1967, Lin and Chern 1985). Pancreatic weight was used to validate $\mathrm{CBV}$; it has been shown that pancreatic hypertrophy results following selective vagotomy (Rümenapf et al., 1994). Finally, urine specific gravity was used in an attempt to asses the effectiveness of the porto-renal osmotic reflex (urine concentration following water deprivation) which has been suggested to be disrupted following HBV (Adaichi Niijima and Jacobs 1976).

Three days after the last experiment, each rat was food and water deprived for $24 \mathrm{~h}$. Thereafter, it was anesthetized with iv pentobarbital $(50 \mathrm{mg} / \mathrm{kg})$ anesthesia and its abdomen was opened via a midline laparotomy. Urine was taken from the bladder with a needle attached to a $1 \mathrm{cc}$ syringe, transferred to a polypropylene vial and later analyzed for specific gravity using a refractometer. Additionally, the pancreas and stomach were isolated, removed, and weighed.

\section{Data Processing and Analysis}

The change in colonic temperature from it's value at time zero $\left(\Delta \mathrm{T}_{\mathrm{c}}\right)$ was the dependent variable and differences within groups were assessed using a one-way analysis of variance (ANOVA) across time followed by a paired student's $t$ test. Differences between groups were measured using two-way repeated measures ANOVA followed by Scheffe's post-hoc test. The fever index was calculated by taking 
the integral of each $\Delta \mathrm{T}_{\mathrm{c}}$ curve over the time $0-4 \mathrm{~h}$ postinjection. The obtained fever indices as well as body weight, relative stomach weight, relative pancreatic weight and urine specific gravity were compared using one-way ANOVA. Relative stomach weight, relative pancreatic weight and urine specific gravity were used to separate treatment groups and compared using three-dimensional randomization-based cluster analysis (performed by Dr. L.D. Homer). A $P$ value equal to or less than 0.05 was always taken to be significant. All data are presented as means \pm SE. 


\section{CHAPTER 4}

\section{RESULTS}

\section{Febrile Responsiveness}

To the relatively low dose of LPS used in this study, the temperature responses observed in these rats were quite heterogeneous. Some animals (HBV) responded with no temperature rise. Others responded with monophasic fevers (temperature rises having a single peak), while still others responded with fevers having biphasic character (temperature rises having two peaks). The initial values of $\mathrm{T}_{\mathrm{c}}$ measured in all four groups of rats were similar $(P=0.889$; listed in the legends to Figs. $2-5)$. To the iv injection of LPS, the thermal responses of the SV, CBV, and GBV rats were similar to each other $(P>0.446)$. In the $\mathrm{SV}$ group, $\mathrm{T}_{\mathrm{c}}$ began to rise following a $40 \mathrm{~min}$ latency and reached a maximal $\mathrm{T}_{\mathrm{c}}$ rise of $0.7 \pm 0.1^{\circ} \mathrm{C}$ at $c a .130 \mathrm{~min}$; this rise was significant $(P$ $<0.001)$ compared to the preinjection colonic temperature. $T_{C}$ remained elevated for the duration of the recording period (Fig. 2). In the CBV treatment group, there was a significant $(P<0.001) \mathrm{T}_{\mathrm{C}}$ rise that began after a $40 \mathrm{~min}$ latency, reached its peak at 140 min poststimulus with a $\mathrm{T}_{\mathrm{c}}$ rise of $0.6 \pm 0.1^{\circ} \mathrm{C}$ above its preinjection level and remained elevated for the duration of the recording (see Fig. 3). In like manner, the GBV group responded to the LPS injection with a fever that began 30 min postinjection reaching its maximal $\mathrm{T}_{\mathrm{C}}$ rise of $0.9 \pm 0.2^{\circ} \mathrm{C}$ at $130 \mathrm{~min}(P<0.001)$ (Fig. 4). 
Rats in the experimental group, HBV, responded differently to the iv injection of $E$. coli endotoxin as compared to the control groups $(P=0.022)$. Following a 50 min latency, $\mathrm{T}_{c}$ began to increase and at $140 \mathrm{~min}$ reached a maximal rise of $0.1 \pm$ $0.2^{\circ} \mathrm{C}$ above its preinjection level (Fig. 5). This rise was not significant $(P=0.665)$. Moreover, this response was not statistically different from the thermoregulatory responses recorded during the time control $(P=0.268)$.

In the time control experiments, when no LPS was given, the slow but steady $\mathrm{T}_{\mathrm{c}}$ decline was similar in all four groups $(P=0.842)$. In the $\mathrm{SV}, \mathrm{CBV}$, and GBV groups, this response was different from the thermoregulatory response seen following the administration of LPS $(P<0.001$, respectively).

The fever index further indicates that the thermal response of the HBV rats to the LPS injection was different from that of the control groups. Figure 6 shows the fever index of each group. Whereas GVB, CVB, and SV animals responded with fevers of approximately the same magnitude $\left(103 \pm 31^{\circ} \mathrm{C} \min , 70 \pm 27^{\circ} \mathrm{C} \min , 83 \pm 17\right.$ ${ }^{\circ} \mathrm{C}$ min, respectively), $\mathrm{HBV}$ rats responded with no fever $\left(-25 \pm 36^{\circ} \mathrm{C} \mathrm{min}\right)$. This difference was statistically different $(P=0.022)$.

\section{Effectiveness of Vagotomy}

At the time of death, the body weight of animals in the four groups (SV, CBV, GBV, HBV) was not different ( $324 \pm 13 \mathrm{~g}, 341 \pm 8 \mathrm{~g}, 335 \pm 13 \mathrm{~g}$, and $346 \pm 18 \mathrm{~g}$, respectively; $P=0.652$ ). However, relative stomach weight was higher in the GBV group $(1.40 \pm 0.21 \mathrm{~g})$ compared to animals in either the SV $(0.61 \pm 0.02 \mathrm{~g}), \mathrm{CBV}$ $(0.83 \pm 0.06 \mathrm{~g})$, or HBV $(0.66 \pm 0.03 \mathrm{~g})$ groups $(P<0.001)$. Similarly, relative pancreatic weight was statistically higher $(P=0.006)$ in the CBV group $(0.41 \pm 0.02 \mathrm{~g})$ 
than in either the SV $(0.32 \pm 0.01 \mathrm{~g})$ or the $\mathrm{HBV}(0.32 \pm 0.02 \mathrm{~g})$ groups. Interestingly, post-hoc analysis revealed that pancreatic weight was not significantly higher in the CBV group than in the GBV group $(0.37 \pm 0.02 \mathrm{~g})$. Urine specific gravity was not significantly different between the groups $(P=0.165)$.

It has been shown previously (Romanovsky et al., Febrile responsiveness, in press) that stomach mass increases as a result of the loss of smooth muscle tone and the consequent retention of food over $24 \mathrm{~h}$ in vagotomized rats. In this study, increased stomach mass of the GBV group demonstrated successful selective gastric vagotomy.

Following selective celiac vagotomy, rats in the CBV group were shown to undergo pancreatic hypertrophy. The increase in pancreas weight was used to demonstrate the successful transection of the celiac vagal branches. The hypertrophy seen in the CBV group was not, however, different from that seen in the GBV group, although it was greater than that observed in HBV rats or sham controls. This is not surprising. The gastric branch of the vagus nerve has descending projections that terminate in the pancreas (Powley et. al. 1983). Indeed, it was shown in a separate study that selective GBV resulted in pancreatic hypertrophy (Rümenapf et al., 1994).

Urine specific gravity was to be used as an index of completeness of HBV. It was suggested earlier that hepatic branch vagotomy disrupts the porto-renal osmotic reflex and as a result, following a 24-h water deprivation, these rats are unable to concentrate their urine (Adachi Niijima and Jacobs 1976). However, the presence of osmoreceptors found elsewhere substantially reduces the strength of this argument. In fact, it is suggested that information from the hepatic osmoreceptors is integrated with that of hypothalamic osmoreceptors in the maintenance of body-fluid homeostasis 
(Adachi Niijima and Jacobs 1976, Morita et al., 1997). The central osmoreceptors can, therefore, easily compensate for the lack of osmotic information from the hepato-portal region.

Utilizing these three measured parameters (stomach mass, pancreatic mass, and urine specific gravity) we were able to separate the four treatment groups into four distinct clusters $(P<0.020$; see Figs 7-8). This confirms that each type of vagotomy had a different effect on the parameters measured. 


\section{Figure Legends}

Fig. 1. Three types of selective subdiaphragmatic vagotomy, viz., celiac, gastric, and hepatic, are shown on a schematic representation of the typical distribution of the rat abdominal vagal branches. Abbreviations used: $a c b$, anterior celiac branch; $a g b$, anterior gastric branch; $a v t$, anterior vagal trunk; $c c b$, common celiac branch; $e p$, esophageal plexus; $h b$, hepatic branch; $l v n$, left vagus nerve; $p c b$, posterior celiac branch; $p g b$, posterior gastric branch; $p v t$, posterior vagal trunk; and $r v n$, right vagus nerve. For the sake of clarity, two simplifications are made. First $\left({ }^{*}\right)$, the dorsal esophageal surface is shown as if the serosa was cut along the right side of the esophagus, partially separated from its underlying tissues, and laid in a frontal plane; the posterior vagal trunk was transected immediately below the diaphragm. Second $\left({ }^{* *}\right)$, the posterior gastric branch is shown only to the level of the lesser gastric curvature with the distal portion being entirely omitted.

Fig. 2. The effect of the iv injection (arrow) of lipopolysaccharide (LPS; 0 or $1 \mu$ $\mathrm{g} / \mathrm{kg})$ on the colonic temperature $\left(\mathrm{T}_{\mathrm{c}}\right)$ of sham-vagotomized rats. For the two doses, the initial values of $T_{c}$ were $37.9 \pm 0.1$ and $37.8 \pm 0.2^{\circ} \mathrm{C}$, respectively.

Fig. 3. The effect of iv LPS ( 0 or $1 \mu \mathrm{g} / \mathrm{kg})$ on the colonic temperature $\left(T_{c}\right)$ in rats with selective celiac vagotomy. For the two doses, the initial values of $T_{c}$ were $38.1 \pm$ 0.1 and $38.0 \pm 0.1^{\circ} \mathrm{C}$, respectively. 
Fig. 4. The effect of iv LPS ( 0 or $1 \mu \mathrm{g} / \mathrm{kg}$ ) on the colonic temperature $\left(T_{c}\right)$ in rats with selective gastric vagotomy. For the two doses, the initial values of $T_{c}$ were $37.9 \pm$ 0.1 and $38.0 \pm 0.2^{\circ} \mathrm{C}$, respectively.

Fig. 5. The effect of iv LPS ( 0 or $1 \mu \mathrm{g} / \mathrm{kg}$ ) on the colonic temperature $\left(T_{c}\right)$ in rats with selective hepatic vagotomy. For the two doses, the initial values of $T_{c}$ were $38.0 \pm$ 0.1 and $38.0 \pm 0.2^{\circ} \mathrm{C}$, respectively.

Fig. 6. The fever index (calculated over the 0-240-min period) of rats with four different types of vagotomy. Fever was induced by the iv injection of LPS $(1 \mu \mathrm{g} / \mathrm{kg})$.

Fig. 7. Separation between four groups of vagotomized rats in the pancreas mass/stomach mass plane. Each group is shown as an oval; the coordinates of the center of the oval are the group means; the greater and lesser diameter of the oval are equal to the corresponding mean's doubled standard error.

Fig. 8. Separation between four groups of vagotomized rats in the stomach mass/urine specific gravity plane. Each group is shown as an oval; the coordinates of the center of the oval are the group means; the greater and lesser diameter of the oval are equal to the corresponding mean's doubled standard error. 


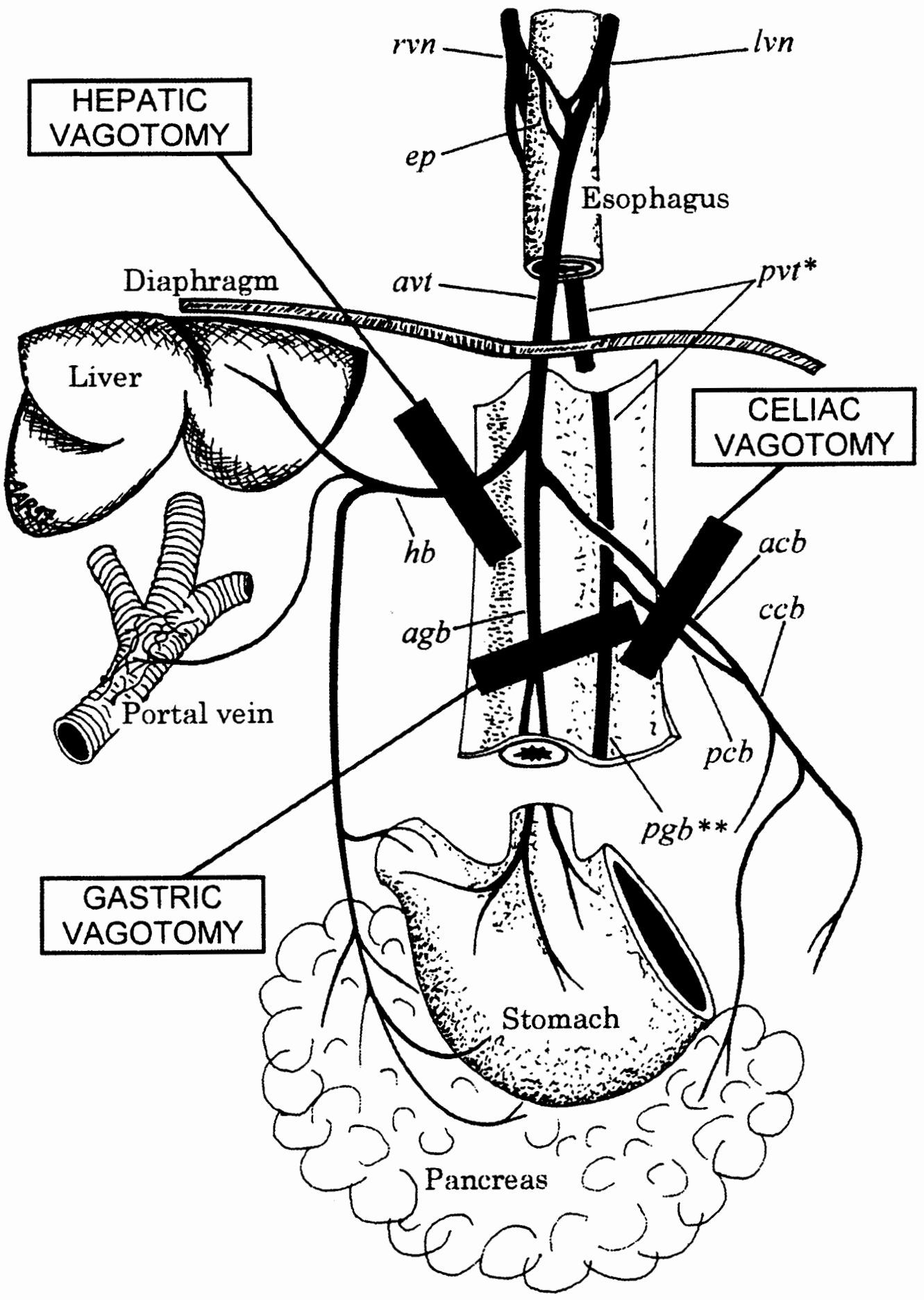




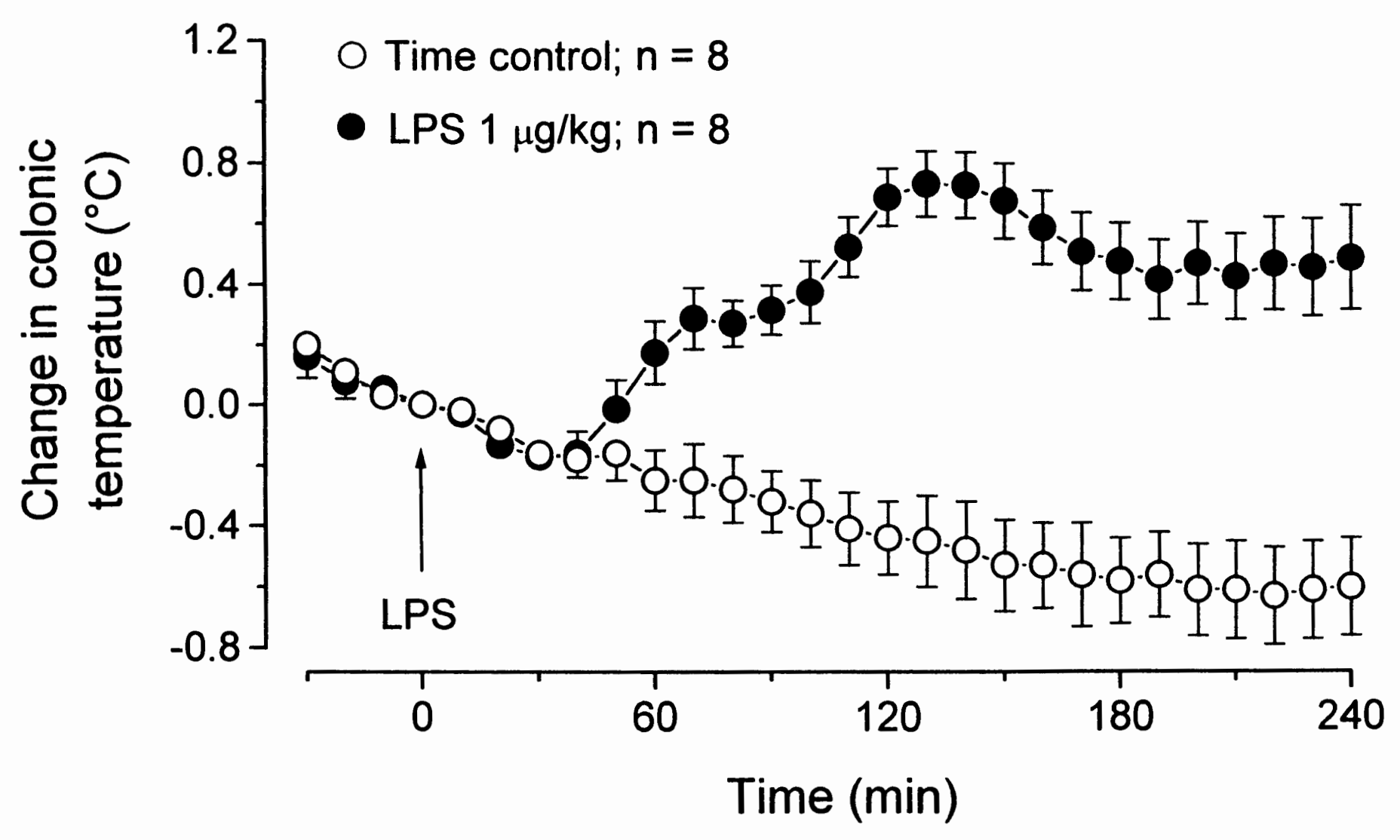




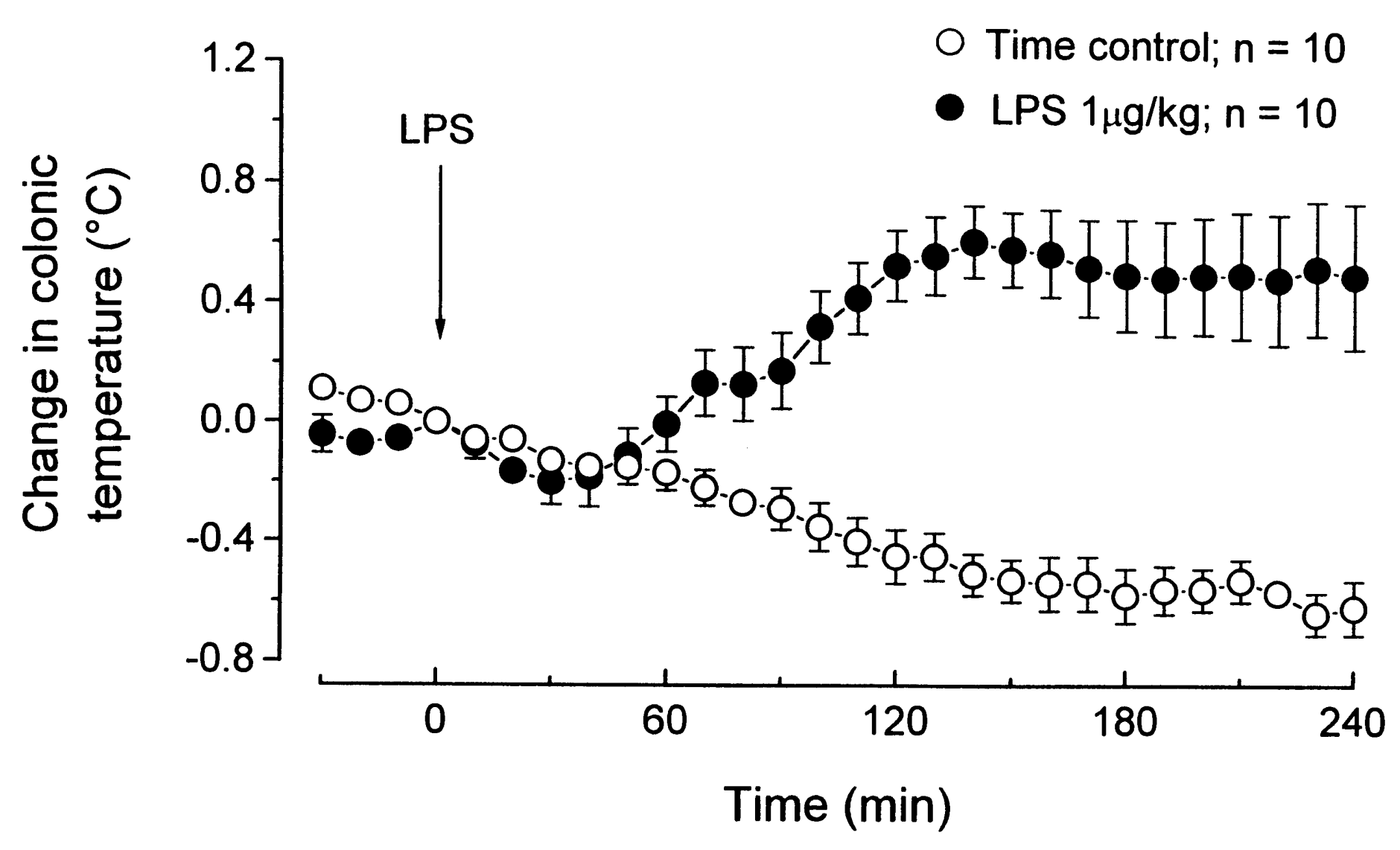




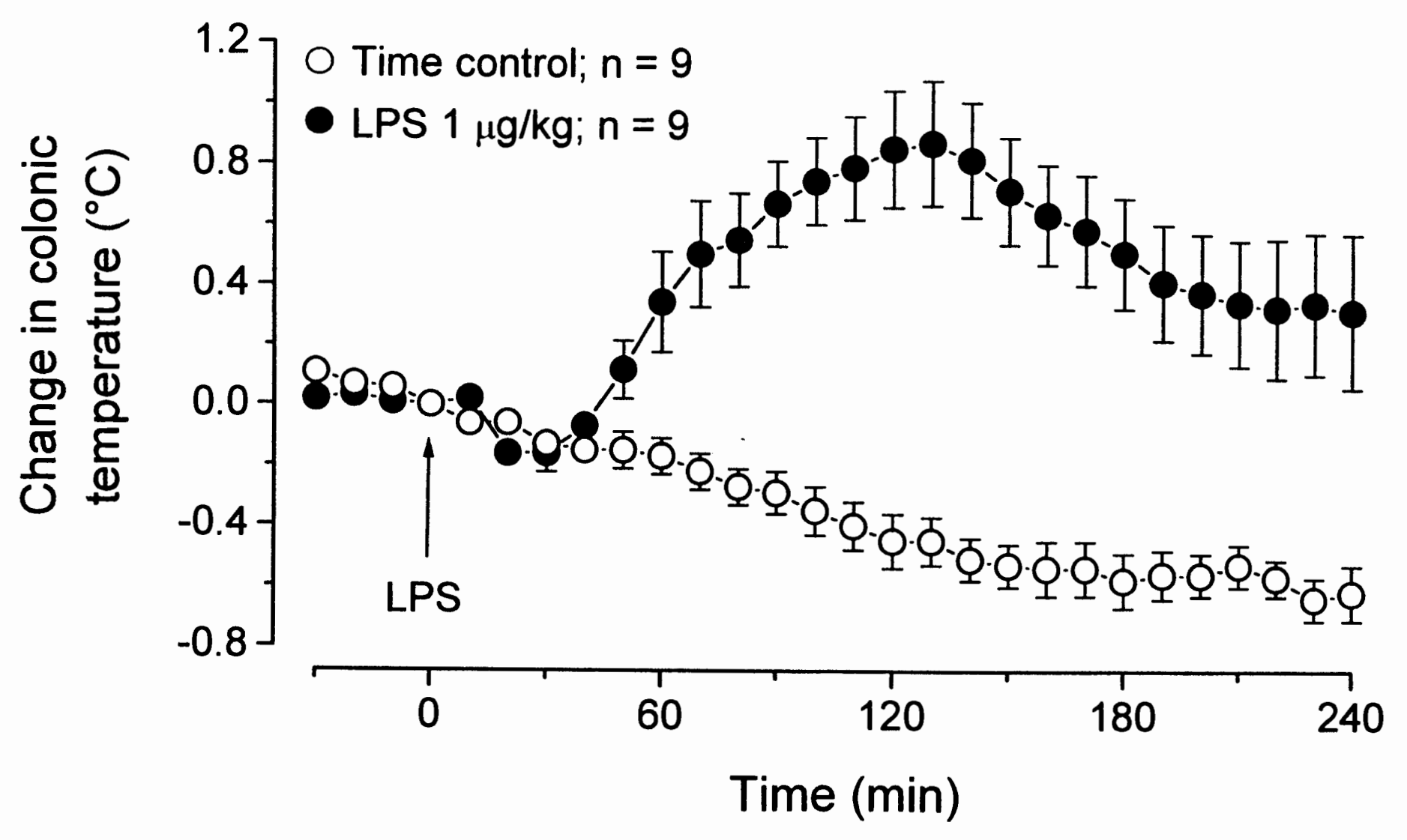




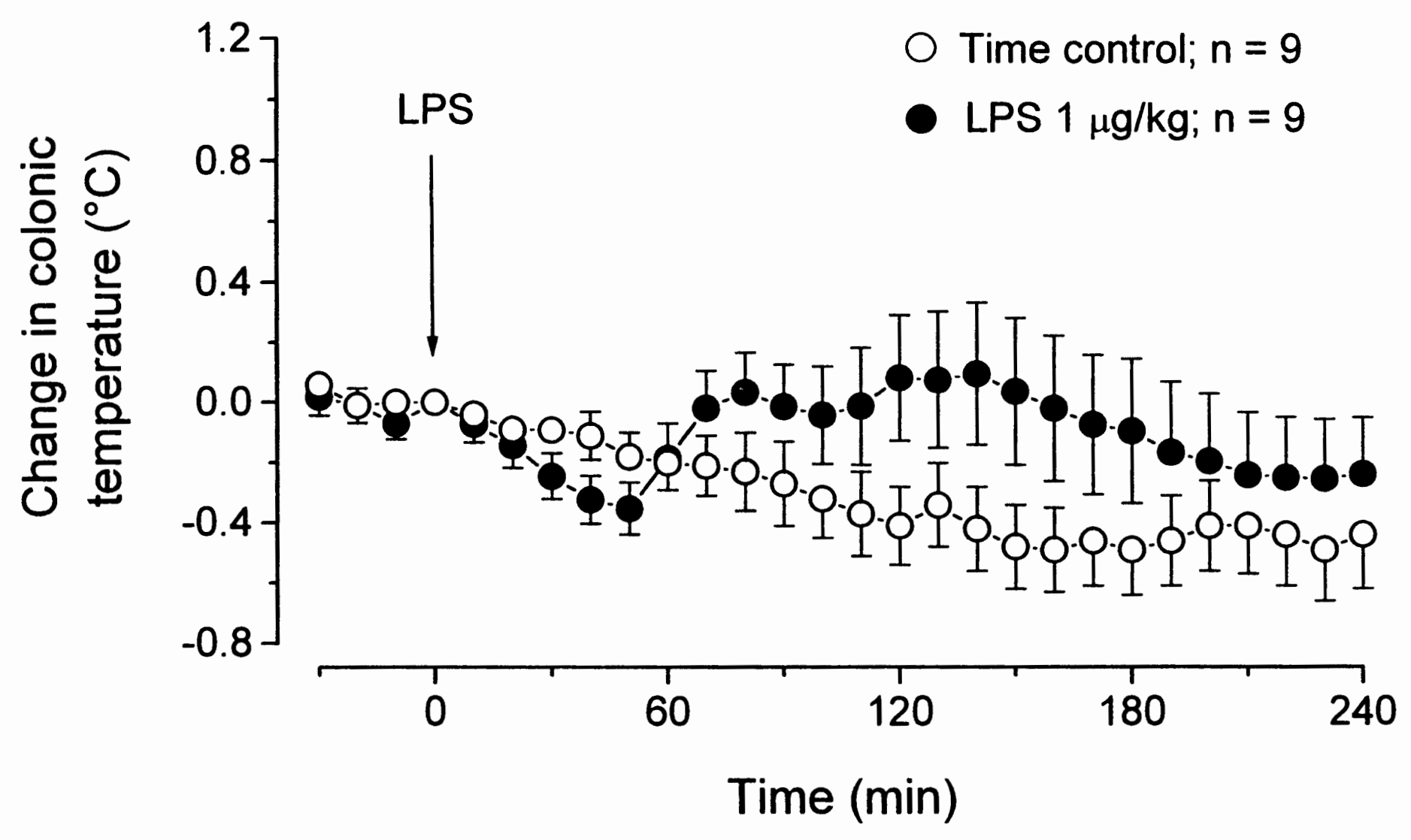




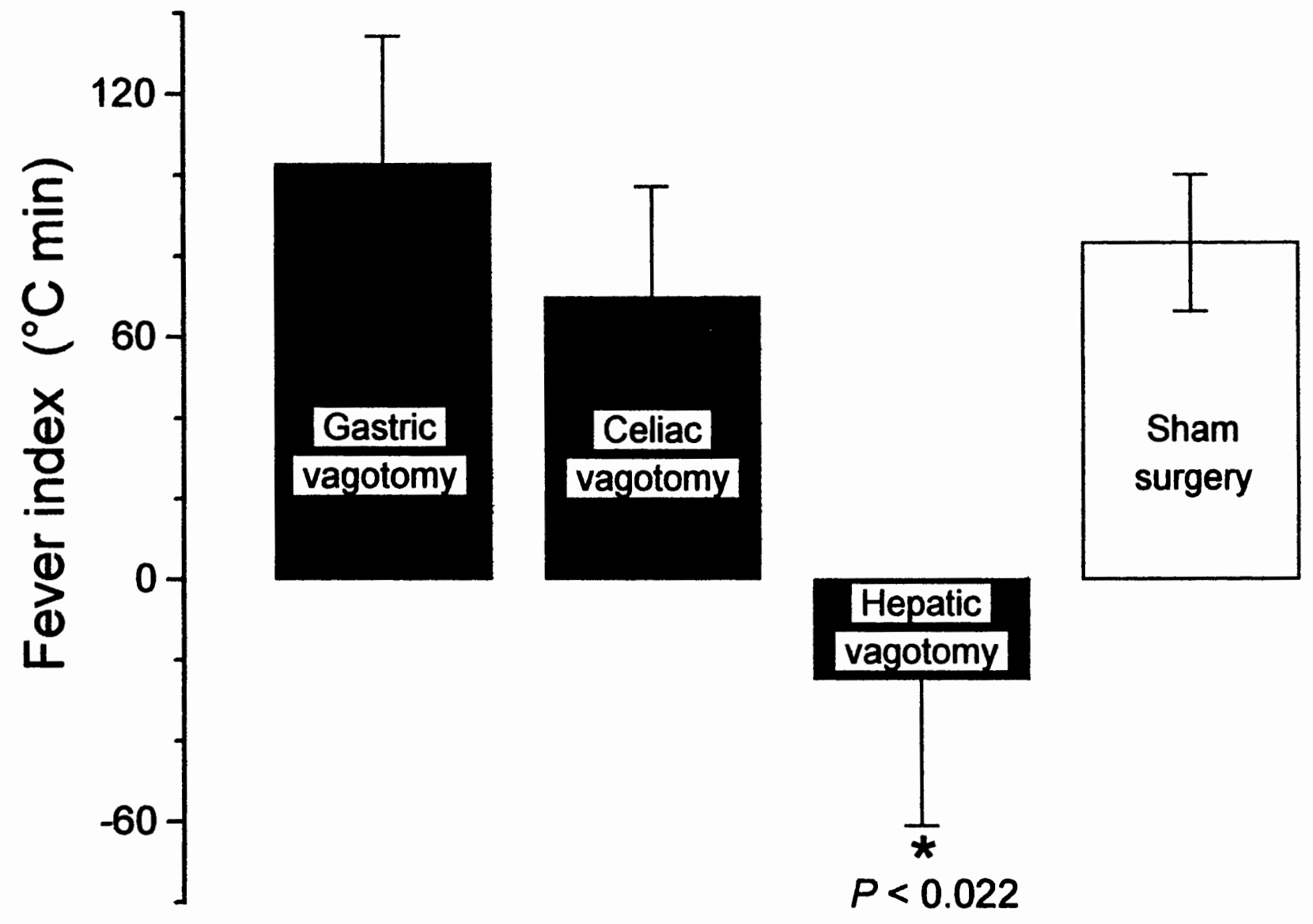




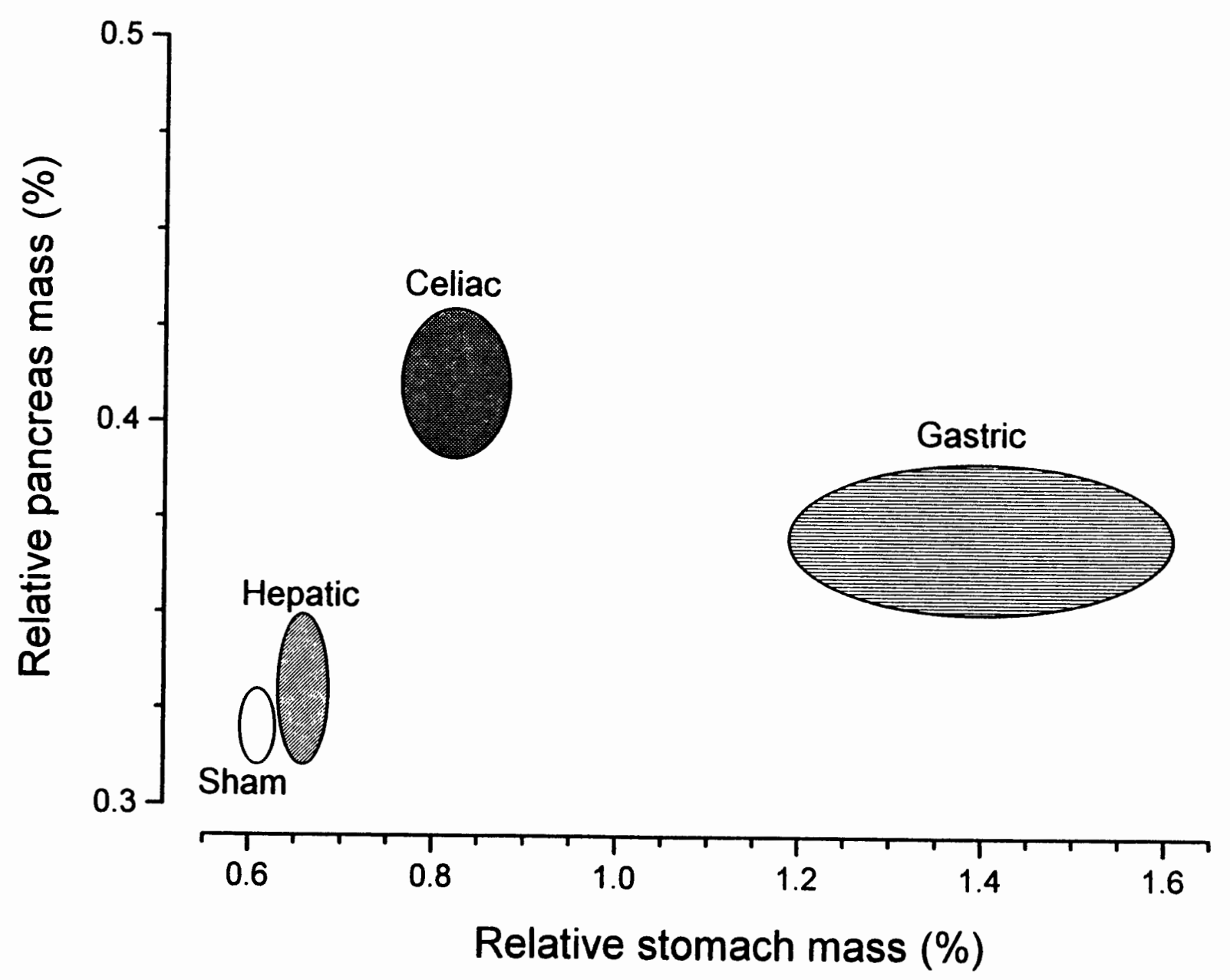




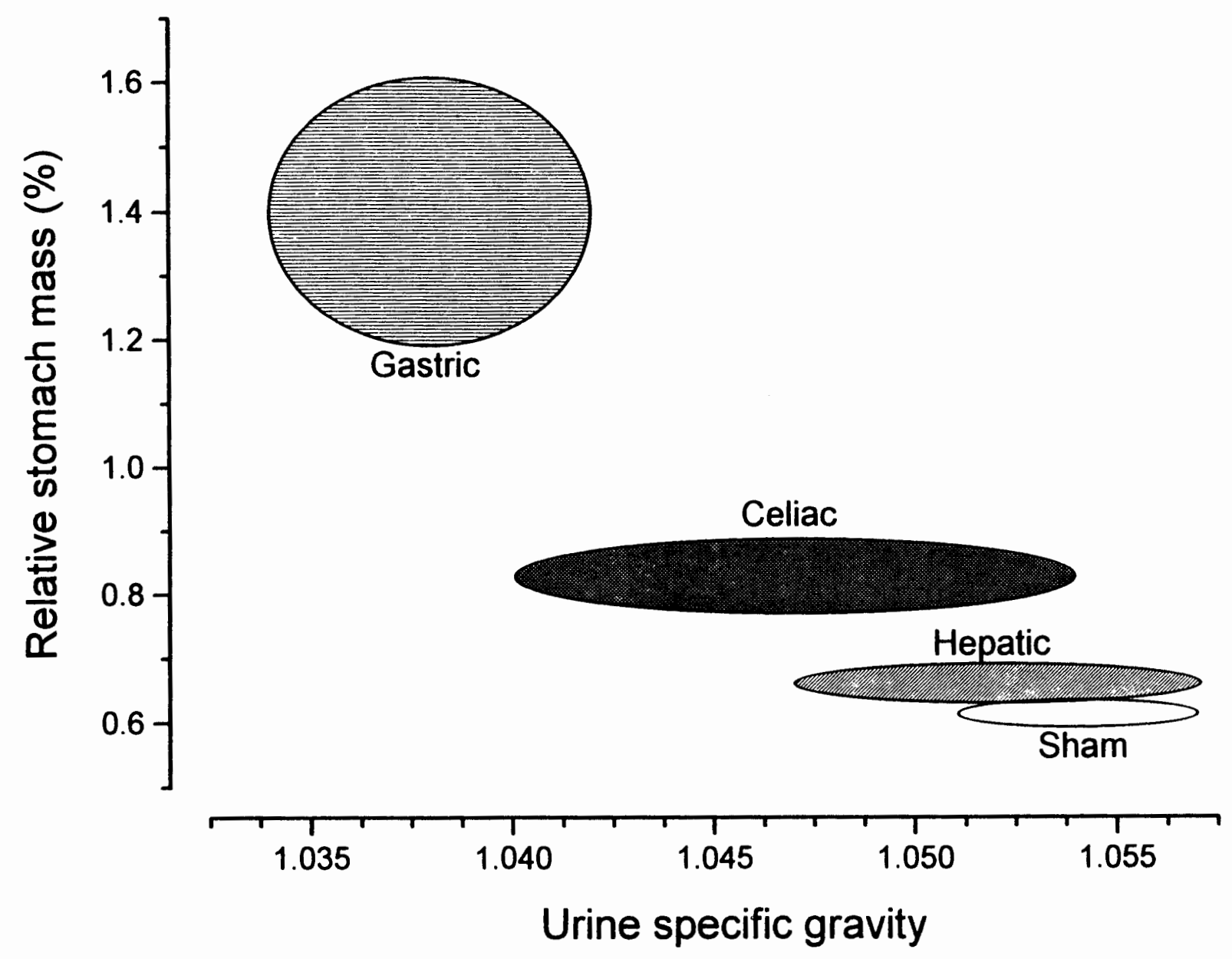




\section{CHAPTER 5}

\section{DISCUSSION}

\section{The Effect of Vagotomy on Fever}

The vagus nerve has been shown to have a role in the pathogenesis of fever. Complete subdiaphragmatic vagotomy blocks the thermal response to $I L-1 \beta$ in rats (Watkins et al., 1995) and LPS in guinea pigs (Sehic and Blatteis 1996). Three alternative explanations of the data have been rejected. First, malnutrition-associated thermoeffector incompetence could, potentially, explain the lack of a febrile response to pyrogens. Malnutrition is known to be a prevalent complication associated with vagotomy (Mordes Herrera and Silen 1977). However, febrile irresponsiveness was shown to occur even in the absence of malnutrition (Romanovsky et al., Febrile responsiveness, in press). Second, vagotomy per se, may alter the response of thermoeffectors to pyrogens. Vagotomized rats have been reported to respond to cold exposure with metabolic rises insufficient to maintain homeothermy (Lin and Chern 1985). In addition, the involvement of the vagus nerve in vasomotor control (Grundy and Davidson 1981) suggests that vagotomized animals may also have functional alterations in their heat conservation mechanisms (i.e. thermoregulatory skin vasoconstriction). However, a recent study has shown that vagotomized rats are able to respond to thermogenic stimuli (cold exposure, adrenergic agonists, stress) equally as well as their sham counterparts (Romanovsky et al., Cold defense, in press). Finally, 
vagotomy may induce endogenous antipyresis. Vagotomized rats and shams were found, however, to respond to icv $\mathrm{PGE}_{2}$ with hyperthermia of equal magnitude (Sugimoto et al., 1997). Thus, endogenous antipyresis does not explain the febrile irresponsiveness of vagotomized rats.

The aforementioned studies do not distinguish between the role of the afferent and efferent pathways of the vagus nerve. It could be speculated that efferent pathways are necessary for LPS to stimulate cytokine production from macrophages. For instance, perhaps Kupffer cells, like alveolar macrophages (Mathison et al. 1994), become refractory to the release of febrigenic mediators due to the lack of efferent information. Alternatively, efferent nerve fibers may be needed for generating a thermogenic response from the abdominal effector organs (brown adipose tissue, liver, etc.). However, following abdominally-localized capsaicin desensitization [which is known to affect only intra-abdominal afferents (Holzer 1988)] an attenuation of the thermal response to intravenous LPS was observed (Székely Balaskó and Romanovsky 1995). Moreover, sickness behavior was blocked in vagotomized rats only when IL-1 was given systemically-central injections elicited normal sickness behavior. When these data are combined with the previously mentioned results that vagotomized rats respond to thermogenic stimuli with the same magnitude of $T_{c}$ rise as sham-operated controls (Romanovsky et al., Cold defense, in press), it becomes apparent that only the vagal afferents are involved in the pathogenesis of fever.

\section{The Hepatic Branch and Fever}

The present study indicates that the role of febrile signal transduction following the injection of a low dose of LPS is ascribed exclusively to the hepatic vagal branch. 
Other studies have confirmed the importance of the liver in producing pyrogenic signals. In studies where the liver Kupffer cells are selectively inactivated using gadolinium chloride $\left(\mathrm{GdCl}_{3}\right)$, the febrile response to low doses of LPS is blocked in guinea pigs (Sehic et al., 1996). [ $\mathrm{GdCl}_{3}$ pretreatment inactivates macrophages systemically. However, Kupffer cells are the last to recover (on day 4). Therefore, by testing the animals $3 \mathrm{~d}$ after $\mathrm{GdCl}_{3}$ treatment, liver Kupffer cells are selectively inactivated]. Similarly, the first phase of biphasic fever is attenuated in rats with congested liver as a result of chronic intraportal catheterization (Székely et al., 1997). Thus, when these studies are combined with the present data, the importance of the hepato-portal region becomes clear. Signals originating in this area act locally by stimulating the hepatic vagal afferents thus activating a (potentially) much faster avenue of signal transduction than the circulating signals involved in the humoral pathway.

The finding that the hepatic vagal branch is intimately involved in febrigenesis seems to be in disagreement with a previous study suggesting the hepatic vagus is not involved in the pathogenesis of fever (Watkins et. al. 1995). This can be explained, however, by analyzing the temporal pattern of the sickness syndrome. The sickness syndrome is characterized by dose-dependent, time-specific behavioral and physiological responses to pathological conditions. These responses include fever, alterations in nociception, and changes in motor activity (Romanovsky et al., 1996). The early phase of the sickness syndrome is characterized by monophasic fever (or the first phase of biphasic fever), and hyperalgesia, among other symptoms. These same responses are mediated by the vagus nerve. The late phase of the sickness syndrome is characterized by fever or hypothermia and hypoalgesia. Subdiaphragmatic vagotomy blocks monophasic fevers only, while biphasic fever in response to higher doses is not 
altered (Romanovsky et al., The vagus nerve, in press). Thus, there is no reason to expect that late phase events will be altered. This is, in fact, the very stage of fever that the previous authors studied (Watkins et al., 1995). Moreover, in a separate study, they documented the blockage of LPS-induced hyperalgesia (an early phase event) (Watkins et al., Neurocircuitry, 1994). This finding suggests that other early phase events-like fever—should also be blocked by selective hepatic vagotomy. What may have prevented these authors from observing the attenuated fever?

It is known that in response to stress, rats can develop hyperthermia on the order of $2^{\circ} \mathrm{C}$ higher than their non-stressed, resting body temperature (Gordon, 1993). Many procedures are known to induce this response including handling, restraint, and injections. To minimize this response, it is absolutely necessary to take specific precautions aimed at preventing stress. This can include repeated exposures to handling, restraint, and experimental procedures (i.e. training). Whereas many authors practice the aforementioned procedures, the method of injection is often overlooked. Injections through a previously implanted catheter (such as iv injections) are much less likely to induce stress because the animal does not feel the injection. In contrast, an animal undergoing ip (or for that matter intramuscular and subcutaneous) injections must first be picked up and then pierced with a needle. This procedure will routinely induce stress hyperthermia. Indeed, this is the case with the previous hepatic vagotomy paper.

The act of delivering the drug via the ip method prevented the authors from observing any attenuation of febrile responsiveness that might have occurred. The hyperthermia resulting from the ip injection resulted in an increase of body temperature of more than $1^{\circ} \mathrm{C}$ that lasted approximately $1 \mathrm{hr}$ postinjection. That magnitude of the 
hyperthermia can easily mask the early phase febrile response (or lack thereof).

Therefore, although they studied early phase symptoms, their methodology did not allow them to effectively study early rises in $T_{b}$. The fact that stress hyperthermia has no bearing on the hyperalgesic response to LPS allowed these researchers to document the lack of hyperalgesia (another early phase sickness symptom) following hepatic branch vagotomy.

\section{Febrile Mechanism}

Recently, a mechanism of fever has been advanced that suggests liver Kupffer cells provide the signal that initiates the febrile response (Blatteis and Sehic 1997). Indeed, when Kupffer cells are inactivated with gadolinium chloride, LPS fever is abolished (Sehic et al. 1996). What chemical mediators are responsible for activating the hepatic vagus nerve?

It is unlikely that LPS, of itself, is able to stimulate the vagal afferents because neurons are not known to possess the requisite LPS receptors (Blatteis and Sehic 1997). Therefore, other mediators are most likely responsible for activating the hepatic vagus and initiating the febrile cascade. Pyretic cytokines, although not detectable in blood until after the onset of fever, may be produced locally in concentrations sufficient enough to stimulate their receptors in the area. Indeed, Kupffer cells are capable of producing cytokines tonically in low concentrations (Decker 1990) presumably due to the continuous low-grade exposure of these cells to bacterial products in the portal blood. Moreover, IL-1 $\beta$ receptors have been localized to hepatic vagal branchassociated paraganglia (Goehler et al., 1994). This provides an excellent pathway by 
which vagal terminals could, potentially, be quickly stimulated by liver macrophage secretory products.

PGE is also known to be produced from activated Kupffer cells (Nathan 1987, Decker 1990). It could be speculated that this chemical provides the stimulating signals. Indeed, PGE receptors have been identified on vagal terminals (Blatteis, personal communication). In addition, the increased discharge rate from the hepatic vagus in response to $I L-1 \beta$ was suppressed by the intraportal administration of sodium salycilate (Niijima 1992). Thus, another mechanism exists by which vagal afferents could be stimulated. However, until more work is completed in this area, this mechanism remains speculative.

Of course it is entirely possible that other, thus far undetermined, Kupffer cell secretory products are responsible for exciting the afferent hepatic vagal branch. In addition to IL-1 and PGE, Kupffer cells (and other liver cells) are capable of secreting other potential mediators including nitric oxide and platelet-activating factor. Further investigation is needed, however, to determine if these chemicals play a role in the pathogenesis of fever.

Once stimulated, the hepatic vagus is hypothesized to relay its propyretic signal to the medullary mucleus tractus solatarius, the major collector of vagal afferents. The pyrogenic message is then postulated to be passed to the A1/A2 noradrenergic cell group which then transmits it to the POA via the ventral noradrenergic bundle. As a consequence, norepinepherine is released in these sites, stimulating, in turn, the local release of PGE (Blatteis and Sehic 1997). As a result, fever develops.

This mechanism is hypothesized to be important only when the LPS is concentrated in the hepato-portal region (Romanovsky et al. The vagus nerve, in 
press). Indeed, fevers induced by higher doses of pyrogens are either completely independent of the vagus or, more likely, involve both vagal and nonvagal mechanisms acting synergistically. Under these conditions, the nonvagal mechanisms are able to easily compensate for the absence of vagal afferentation resulting from vagotomy. 


\section{CHAPTER 6}

\section{SUMMARY}

The purpose of this study was to identify the specific vagal branch that is involved in the transduction of a pyrogenic signal from the periphery to the brain. The data provide evidence that the hepatic vagal branch exclusively plays an important role in mediating febrile signals in response to systemic, low doses of LPS. An important corollary to this result is that it reconciles the apparent dichotomy whereby one early phase sickness symptom (i.e. hyperalgesia) is mediated by the hepatic vagus but not another (i.e. fever). Finally, it is speculated that the results reported here lend support to the emerging hypothesis that pyrogenic signals originating in the liver Kupffer cells are responsible for initiating febrigenesis. 


\section{CHAPTER 7}

\section{PERSPECTIVES}

The role of the vagus nerve in febrile pathogenesis is an exciting new development in the study of fever. However, at this point, four major questions still exist.

First, identifying the chemicals secreted by Kupffer cells that activate vagal afferents is an important step in understanding the mechanism of febrigenesis. Whereas pyrogenic cytokines appear to be the most probable mediators, Kupffer cells are able to secrete a variety of chemicals that may have mediatory properties. The systematic evaluation of these substances is necessary to characterize the immune-to-brain interactions that occur during systemic inflammation. Moreover, understanding the conditions under which these chemicals are released will aid researchers in understanding other neuro-immune interactions such as those involved with hyperalgesia and the depression of social interaction following LPS administration.

Second, previous studies have affirmed a role of the OVLT in febrigenesis. How may the peripheral pyrogenic signaling of cytokines (or other mediators) via the proposed neural pathway be reconciled with this model? The fact that fever in response to high doses of LPS is not attenuated suggests that, perhaps, the OVLT is important in the late phases of fever. Thus, does the vagal pathway replace the OVLT 
mechanism or, instead, do the two components act synergistically (or independently) to form an integrated model of fever pathogenesis?

Third, other humoral mechanisms are surely involved in the fever pathway. It has been postulated that besides pro-pyretic mechanisms, antipyretic mechanisms are also activated in the course of all fevers. The ratio between the different mechanisms determines the final direction and course of the body temperature changes (Székely and Romanovsky in press). The involvement of the vagus nerve in these competing mechanisms warrants further study.

Finally, although the vagus nerve certainly has a role in the thermal response to systemic inflammation, it appears to be important only when the pyrogenic challenge is weak. Thus, the vagally carried information from the liver may be critical not under the conditions of severe pathology, but rather under near-normal and normal conditions. May such information influence physiological (as opposed to pathological) thermoregulation? Could the vagus nerve, for example, be involved in postprandial hyperthermia? These questions form an exciting line of opportunities that will allow researchers to investigate the role of the chemosensitive vagal afferents in thermoregulatory phenomena. 


\section{CHAPTER 8}

\section{REFERENCES}

1. Adachi, A., A. Niijima, and H. L. Jacobs. An hepatic osmoreceptor mechanism in the rat: electrophysiological and behavioral studies. Am. J. Physiol. 231(4): 10431049, 1976.

2. Banks, W. A., S. R. Plotkin, A. J. Kastin. Permeability of the blood-brain barrier to soluble cytokine receptors. Neuroimmunomodulation 2: 161-165, 1995

3. Blatteis, C. M. Role of the OVLT in the response to circulating pyrogens. Prog. Brain Res. 91: 409-412, 1992.

4. Blatteis, C. M., S. L. Bealer, W. S. Hunter, J. Llanos-Q, R. A. Ahokas, and T. A. Mashburn Jr. Suppression of fever after lesions of the anteroventral third ventricle in guinea pigs. Brain Res. Bull. 2: 519-526, 1983.

5. Blatteis, C. M., and E. Sehic. Fever: how may circulating pyrogens signal the brain? News Physiol. Sci. 12: 1-9, 1997.

6. Bligh, J., and A. S. Milton. The thermoregulatory effects of prostaglandin $\mathrm{E}_{1}$ when infused into the lateral cerebral ventricle of welsh mountain sheep at different ambient temperatures. J. Physiol. (Lond.). 229: 30-31, 1973.

7. Bluthé, R.-M., K. Michaud, K. Kelley, and R. Dantzer. Vagotomy attenuates behavioral effects of interleukin-1 injected peripherally but not centrally. Neuroreport 7: 1485-1488, 1996.

8. Bluthé, R.-M., V. Walter, P. Parnet, S. Layé, J. Lestage, D. Verrier, S. Poole, B. E. Stenning, K. W. Kelley, and R. Dantzer. Lipopolysaccharide induces sickness behaviour in rats by a vagal mediated mechanism. C. R. Acad. Sci. Paris 317: 499503, 1994. 
9. Cooper, K. E. The neurobiology of fever: thoughts and recent developments. Ann. Rev. Neurosci. 10: 297-324, 1987.

10. Cooper, K. E., and W. I. Cranston. Clearance of radioactive bacterial pyrogen from the circulation (Abstract). J. Physiol. (Lond.). 166: 41-42P, 1963

11. Crawshaw, L. I., and J. T. Stitt. Behavioral and autonomic induction of prostaglandin $\mathrm{E}_{1}$ in squirrel monkeys. J. Physiol. (Lond.). 244: 197-206, 1975.

12. Dascombe, M. J. and A. S. Milton. Study of the possible entry of bacterial endotoxin and prostaglandin E2 into the central nervous system from the blood. Br. J. Pharmacol. 66: 562-572, 1979.

13. Davatelis, G., S. D. Wolpe, B. Sherry, J. M. Dayer, R. Chicheportiche, A. Cerami. Macrophage inflammatory protein-1: a prostaglandin-independent endogenous pyrogen. Science 241: 1066-1068, 1989.

14. Davson, E. S., B. Zlokovik, L. Rakic, and M. B. Segal. An Introduction to the Blood Brain Barrier. Boca Raton: CRC Press Inc., 1993. Pp 1-145.

15. Decker, K. Biologically active products of stimulated liver macrophages (Kupffer cells). Eur. J. Biochem. 192: 245-261, 1990.

16. Dinarello, C. A., H. A. Bernheim, G. W. Duff, H. V. Le, T. L. Nagabhushan, N. C. Hamilton, and F. Coceani. Mechanisms of fever induced by recombinant human interferon. J. Clin. Invest. 74: 906-913, 1984.

17. Dinarello, C. A., J. G. Cannon, and S. M. Wolff. New concepts on the pathogenesis of fever. Rev. Infect. Dis. 10: 168-189, 1988.

18. Dinarello, C. A., J. S. Cannon, S. M. Wolff, H. A. Bernheim, A. Cerome, J. S. Figari, M. A. Pollidino, and J. V. O'Connor. Tumor necrosis factor (cachectin) is an endogenous pyrogen and induces production of interleukin-1. J. Exp. Med. 163: 1433-1450, 1986.

19. Dinarello, C. A., R. S. Elin, L. Chedid, and S. M. Wolff. The pyrogenicity of synthetic adjuvants. J. Infect. Dis. 138: 760-767, 1978.

20. Dinarello, C. A., P. Weiner, and S. M. Wolff. Radiolabeling and disposition in rabbits of purified human leukocytic pyrogen (Abstract). Clin. Res. 26: 522A, 1978. 
21. Dinarello, C. A., and S. M. Wolff. Exogenous pyrogens. In: Pyretics and Antipyretics, ed. by A. S. Milton. New York: Springer, 1982. Pp 74-112.

22. Dinarello, C. A., and S. M. Wolff. The role of interleukin-1 in disease. N. E. J.M. 328: 106-113, 1993.

23. Ellis, H., and J. Pryse-Davies. Vagotomy in the rat. A study of its effects on stomach and small intestine. Brit. J. Exp. Path. 48: 135-141, 1967.

24. Eberle-Wang, K., P. Levitt, and K. J. Simansky. Abdominal vagotomy dissociates the anorectic mechanisms for peripheral serotonin and cholecystokinin. Am.J. Physiol. 265 (Regulatory Integrative Comp. Physiol. 32): R602-R608, 1993.

25. Gegner, J. A., R. J. Ulevitch, and P. S. Tobias. Lipopolysaccharide (LPS) signal transduction and clearance. J. Biol. Chem. 270: 5320-5325, 1995.

26. Goehler, L. E., J. Relton, S. F. Maier, and L. R. Watkins. Biotinylated interleukin1 receptor antagonist (IL1ra) labels paraganglia in the rat liver hilus and hepatic vagus (Abstract). Soc. Neurosci. Abstr. 20: 956, 1994.

27. Goldbach, J.-M., J. Roth, and E. Zeisberger. Fever suppression by subdiaphragmatic vagotomy in guinea pigs depends on the route of pyrogen administration. Am. J. Physiol. 272 (Regulatory, Integrative, Comp. Physiol. 41): R675-R681, 1997.

28. Gordon, C. J. Temperature Regulation in Laboratory Rodents. Cambridge: Cambridge University Press, 1993.

29. Grundy, D., and J. S. Davidson. Cardiovascular changes elicited by vagal gastric afferents in the rat. Q.J. Exp. Physiol. 66: 307-310, 1981.

30. Holzer, P. Local effector functions of capsaicin-sensitive sensory nerve endings: involvement of tachykinins, calcitonin gene-related peptide and other neuropeptides. Neuroscience 24: 739-768, 1988.

31. Kandasamy, S. B., and B. A. Williams. Cholecystokinin-octapeptide-induced hyperthermia in guinea pigs. Experimentia Basel 39: 1282-1284, 1983.

32. Kawasaki, H., M. Moriyama, Y. Ohtani, M. Naitoh, A. Tanaka, and H. Nariuchi. Analysis of endotoxin fever in rabbits using monoclonal antibody to tumor necrosis factor. Infect. Immun. 57: 3131-3135, 1989. 
33. Kirkland, T. N., F. Finley, D. Leturcq, A. Moriarty, J. D. Lee, R. J. Ulevitch, and P. S. Tobias. Analysis of lipopolysaccharide binding by CD14. J. Biol. Chem. 268: 24818-24823, 1993.

34. Kluger, M. J. Fever: role of pyrogens and cryogens. Physiol. Rev. 71: 93-127, 1991.

35. Kluger, M. J. Fever revisited. Pediatrics 90: 846-850, 1992.

36. Kluger, M. J., D. H. Ringler, and M. R. Anver. Fever and survival. Science 188: 166-168, 1975.

37. Krisch, B., H. Leonhardt and W. Buchheim. The functional and structural border between the CSF- and blood- milieu in the circumventricular organs (organum vasculosum laminae terminalis, subfornical organ, area postrema) of the rat. Cell Tissue Res. 195: 485-497, 1978.

38. Krueger, J. M., J. A. Majde, C. M. Blatteis, J. Endsley, R. A. Ahokas, and A. B. Cady. Polyriboinosinic:poilyribocytidylic acid enhances rabbit slow wave sleep. Am. J. Physiol. 255 (Regulatory Integrative Comp. Physiol.): R748-R755, 1988.

39. Layé, S., R.-M. Bluthé, S. Kent, C. Combe, C. Médina, P. Parnet, K. Kelley, and R. Dantzer. Subdiaphragmatic vagotomy blocks the induction of $\mathbb{L}-1 \beta \mathrm{mRNA}$ in the brain of mice in response to peripheral LPS. Am. J. Physiol. 268 (Regulatory Integrative Comp. Physiol. 37): R1327-R1331, 1995.

40. Le, J., and J. Vilcek. Biology of disease. Interleukin 6: a multifunctional cytokine regulating immune reactions and the acute phase protein response. Lab. Invest. 61: 588-602, 1989.

41. LeMay, L. G., I. G. Otterness, A. J. Vander, and M. J. Kluger. In vivo evidence that the rise in plasma IL-6 following injection of a fever inducing dose of LPS is mediated by IL-1 $\beta$. Cytokine 2: 199-204, 1990.

42. LeMay, L. G, A. J. Vander and, M. J. Kluger. Role of interleukin-6 in fever in the rat. Am. J. Physiol. 259 (Regulatory Integrative Comp. Physiol.): R798-R803, 1990. 
43. Lin, M. T. and Y. F. Chern. Effects of subdiaphragmatic vagotomy on thermoregulatory responses of rats to different ambient temperatures. Exp. Neurol. 88: 467-470, 1985.

44. Mathison, J. C., and R. J. Ulevitch. The clearance, tissue distribution, and cellular localization of intravenously injected lipopolysaccharide in rabbits. J. Immunol. 123: 2133-2143, 1979.

45. Mathison, R., L. Carter, C. Mowat, E. Bissonnette, J. S. Davison, and A. D. Befus. Temporal analysis of the anti-inflammatory effects of decentralization of the rat superior cervical ganglia. Am. J. Physiol. 266 (Regulatory integrative Comp. Physiol. 35): R1537-R1543, 1994.

46. Miossec, P. and M. Ziff. Immune interferon enhances the production of interleukin-1 by human endothelial cells stimulated with lipopolysaccharide. $J$. Immunol. 137: 2848-2852, 1986.

47. Moltz, H. Fever: causes and consequences. Neurosci. Biobehav. Rev. 17: 237269, 1993.

48. Montuschi, P., G. Tringali, A. Mirtella, L. Parente, E. Ragazzoni, P. Preziosi, and P. Navarra. Interleukin-1 $\beta$ release from rat gastric fundus. Am. J. Physiol. 271 (Gastrointest. Liver Physiol. 34): G275-G281, 1996.

49. Mordes, J. P., M. G. Herrera, and W. Silen. Decreased weight gain and food intake in vagotomized rats. Proc. Soc. Exp. Biol. Med. 156: 257-260, 1977.

50. Morita, H., Y. Yamashita, Y. Nishida, M. Tokuda, O. Hatase, and H. Hosomi. Fos induction in rat brain neurons after stimulation of the hepatoportal Na-sensitive mechanism. Am. J. Physiol. 272 (Regulatory Integrative Comp. Physiol. 41): R913-R923, 1997.

51. Murphy, P. A. Exogenous pyrogens. In: Fever: Basic Mechanisms and Management, ed. by P. A. Mackowiak. New York: Raven Press, 1991. Pp 49-58.

52. Nagai, M., T. Saigusa, Y. Shimada, H. Inagawa, H. Oshima, and M. Iriki. Antibody to tumor necrosis factor (TNF) reduces endotoxin fever. Experimentia Basel 44: 606-607, 1988. 
53. Nakamori, T. A. Morimoto, K. Yamaguchi, T. Watanabe, N. C. Long, and N. Murakami. Organum vasculosum laminae terminalis (OVLT) is a brain site to produce interleukin-1 $\beta$ during fever. Brain Res. 618: 155-159, 1993.

54. Nakao, A., S. Taki, M. Yasui, Y. Kimura, T. Nonami, A. Harada, and H. Takagi. The fate of intravenously injected endotoxin in normal rats and in rats with liver failure. Hepatology 19: 1251-1256, 1994.

55. Nathan, C. F. Secretory products of macrophages. J. Clin. Invest. 79: 319-326, 1987.

56. Niijima, A. The afferent discharges from sensors for interleukin-1 $\beta$ in the hepatoportal system in the anesthetized rat (Abstract). J. Physiol. (Lond.). 446: 236P, 1992.

57. Ogle, C. K., J. Z. Wu, J. W. Alexander, J. E. Fischer, and J. D. Ogle. The effects of in vivo administration of endotoxin on the functions and interaction of hepatocytes and Kupffer cells. Prostaglandins 41:169-183, 1991.

58. Oka, $\mathrm{T}$., and $\mathrm{T}$. Hori. $\mathrm{EP}_{1}$-receptor mediation of prostaglandin $\mathrm{E}_{2}$-induced hyperthermia in rats. Am. J. Physiol. 267 (Regulatory Integrative Comp. Physiol. 36): R289-R294, 1994.

59. Powley, T. L., J. C. Prechtl, E. A. Fox, and H.-S. Berthoud. Anatomical considerations for surgery of the rat abdominal vagus: distribution, paraganglia and regeneration. J. Auto. Nerv. Sys. 9: 79-97, 1983.

60. Reitschel, E. T., Y. B. Kim, D. W. Watson, C. Galanos, O. Luderitz, and O. Westphal. Pyrogenicity and immunogenicity of lipid A complexed with bovine or human serum albumin. Infect. Immun. 8: 173-177, 1973.

61. Romanovsky, A. A., V. A. Kulchitsky, N. V. Akulich, S. V. Koulchitsky, C. T. Simons, D. I. Sessler, and V. N. Gourine. First and second phases of biphasic fever: two sequential stages of the sickness syndrome? Am. J. Physiol. 271 (Regulatory Integrative Comp. Physiol. 40): R244-R253, 1996.

62. Romanovsky, A. A., V. A. Kulchitsky, C. T. Simons, N. Sugimoto, and M. Székely. Febrile responsiveness of vagotomized vats is suppressed even in the absence of malnutrition. Am. J. Physiol. (in press). 
63. Romanovsky, A. A., V. A. Kulchitsky, C. T. Simons, N. Sugimoto, and M. Székely. Cold defense mechanisms in vagotomized rats. Am. J. Physiol. (in press).

64. Romanovsky, A. A., C. T. Simons, M. Székely, and V. A. Kulchitsky. The vagus nerve in the thermoregulatory response to systemic inflammation. Am. J. Physiol. (in press).

65. Rothwell, N. J., A. J. Hardwick, and I. Lindley. Central actions of interleukin-8 in the rat are independent of prostaglandins. Horm. Metab. Res. 22: 595-596, 1990.

66. Rümenapf, G., P. O. Schwille, W. Wagner, F. P. Tiecks, W. Fries, and D. Galewski. Highly selective vagotomy in the rat: effects on bone and mineral metabolism. Scand. J. Gastroenterol. 29: 232-237, 1994.

67. Sehic, E., and C. M. Blatteis. Blockade of lipopolysaccharide-induced fever by subdiaphragmatic vagotomy in guinea pigs. Brain Res. 726: 160-166, 1996.

68. Sehic, E., W. S. Hunter, A. L. Ungar, and C. M. Blatteis. Blockade of Kupffer cells prevents the febrile and preoptic prostaglandin $\mathrm{E}_{2}$ responses to intravenous lipopolysaccharide in guinea pigs (Abstract). In: An Update in Thermoregulation: From Cellular Functions to Clinical Relevance. Memphis, Tennessee, 1996, p. 72.

69. Shibata, M., and C. M. Blatteis. Differential effects of cytokines on thermosensitive neurons in guinea pig preoptic area slices. Am. J. Physiol. 261 (Regulatory Integrative Comp. Physiol. 30): R1096-R1103, 1991.

70. Shalaby, M. R., A. Waage, L. Aarden, and T. Espevik. Endotoxin, tumor necrosis factor a, and interleukin 1 induce interleukin 6 production in vivo. Clin. Immunol. Immunopathol. 53: 488-498, 1989.

71. Shimozato, T., M. Iwata, and N. Tamura. Suppression of tumor necrosis factor alpha production by a human immunoglobulin preparation for intravenous use. Infect. Immun. 58: 1384-1390, 1990.

72. Siegert, $R$, and $P$. Braune. The pyrogens of myxoviruses: resistance of influenza A pyrogen to heat, ultraviolet and chemical treatment. Virology 24: 218-224, 1964.

73. Stitt, J. T. Fever versus hyperthermia. Fed. Proc. 38: 39-43, 1979. 
74. Sugimoto, N., C. T. Simons, M. Székely, and A. A. Romanovsky. Prostaglandin $\mathrm{E}_{2}\left(\mathrm{PGE}_{2}\right)$ hyperthermia in vagotomized rats (Abstract). FASEB J. 11: 527, 1997.

75. Székely, M., M. Balaskó, and A. A. Romanovsky. Capsaicin-sensitive neural afferents in fever pathogenesis (Abstract). Pflügers Arch. 430 (Suppl.): R61, 1995.

76. Székely, M., M. Balaskó, and A. A. Romanovsky. Peripheral neural inputs: their role in fever development. Ann. N. Y. Acad. Sci. 813: 427-434, 1997.

77. Székely, M., and A. A. Romanovsky. Pyretic and antipyretic signals within and without fever: a possible interplay. Med. Hypotheses (in press).

78. Székely, M., C. T. Simons, V. A. Kulchitsky, and A. A. Romanovsky. The abdominal vagus: its presumed role in fever and in non-febrile temperature regulation (Abstract). In: 1997 Symposium on Thermal Physiology. Copenhagen, Denmark, 1997 (in press).

79. Trautwein, C., K. Boker, and M. P. Manns. Hepatocyte and immune system: acute phase reaction as a contribution to early defence mechanisms. Gut 35: 11631166, 1994.

80. Watkins, L. R., L. E. Goehler, J. K Relton, N. Tartaglia, L. Silbert, D. Martin, and S. F. Maier. Blockade of interleukin-1 induced hyperthermia by subdiaphragmatic vagotomy: evidence for vagal mediation of immune-brain communication. Neurosci. Lett. 183: 27-31, 1995.

81. Watkins, L. R., S. F. Maier, and L. E. Goehler. Cytokine-to-brain communication: a review and analysis of alternative mechanisms. Life Sci. 57: 1011-1026, 1995.

82. Watkins, L. R., E. P. Wiertelak, L. E. Goehler, K. P. Smith, D. Martin, and S. F. Maier. Characterization of cytokine-induced hyperalgesia. Brain Res. 654: 15-26, 1994.

83. Watkins, L. R., E. P. Wiertelak, L. E. Goehler, K. Mooney-Heiberger, J. Martinea, L. Furness, K. P. Smith, and S. F. Maier. Neurocircuitry of illness-induced hyperalgesia. Brain Res. 639: 283-299, 1994.

84. Wright, S. D., R. A. Ramos, P. S. Tobias, R. J. Ulevitch, and J. C. Mathison. CD14, a receptor for complexes of lipopolysaccharide (LPS) and LPS binding protein. Science 249: 1431-1433, 1990. 
85. Zuckerman, S. H., J. Shellhaas, and R. D. Butler. Differential regulation of lipopolysaccharide-induced IL-1 and TNF synthesis: Effects of endogenous and exogenous gluccocorticoids and the role of the pituitary-adrenal axis. Eur. $J$. Immunol. 19: 301-305, 1989. 